\title{
Pediatric Airway Maintenance and Clearance in the Acute Care Setting: How To Stay Out of Trouble
}

Brian K Walsh MBA RRT-NPS FAARC, Kristen Hood RRT-NPS, and Greg Merritt RRT-NPS

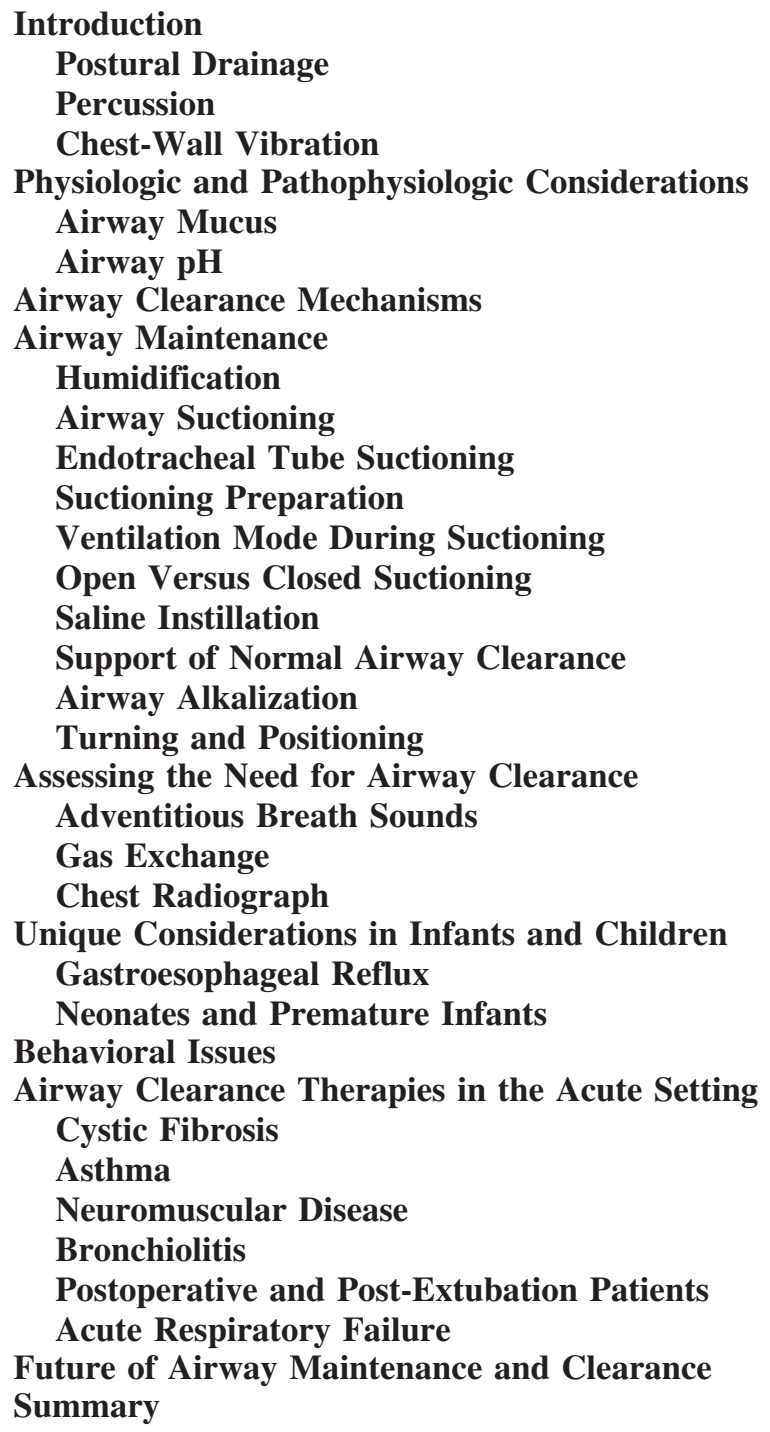

The authors are affiliated with the Department of Respiratory Care, Children's Medical Center Dallas, Dallas, Texas.

Mr Walsh presented a version of this paper at the 47th ReSPIRATORY CARE Journal Conference, "Neonatal and Pediatric Respiratory Care: What Does the Future Hold?" held November 5-7, 2010, in Scottsdale, Arizona.
The authors have disclosed no conflicts of interest.

Correspondence: Brian K Walsh MBA RRT-NPS FAARC, Department of Respiratory Care, Children's Medical Center Dallas, 1935 Medical District Drive, Dallas TX 75235. E-mail: brian.walsh@childrens.com.

DOI: $10.4187 /$ respcare. 01323 
Traditional airway maintenance and clearance therapy and principles of application are similar for neonates, children, and adults. Yet there are distinct differences in physiology and pathology between children and adults that limit the routine application of adult-derived airway-clearance techniques in children. This paper focuses on airway-clearance techniques and airway maintenance in the pediatric patient with acute respiratory disease, specifically, those used in the hospital environment, prevailing lung characteristics that may arise during exacerbations, and the differences in physiologic processes unique to infants and children. One of the staples of respiratory care has been chest physiotherapy and postural drainage. Many new airway clearance and maintenance techniques have evolved, but few have demonstrated true efficacy in the pediatric patient population. Much of this is probably due to the limited ability to assess outcome and/or choose a proper disease-specific or age-specific modality. Airway-clearance techniques consume a substantial amount of time and equipment. Available disease-specific evidence of airway-clearance techniques and airway maintenance will be discussed whenever possible. Unfortunately, more questions than answers remain. Key words: pediatric; airway clearance; respiratory; chest physiotherapy; cystic fibrosis. [Respir Care 2011;56(9):1424-1440. () 2011 Daedalus Enterprises]

\section{Introduction}

Traditional airway maintenance, airway clearance therapy, and principles of their application are similar for neonates, children, and adults. In the pediatric patient, distinct differences in physiology and pathology limit the application of adult-derived airway clearance and maintenance modalities. This paper focuses on the pediatric airway clearance and maintenance aspect of acute respiratory diseases, specifically in the hospital environment, biophysical and biochemical characteristics of the lung that prevail during pulmonary exacerbations, physiology and pathological processes unique to children, and other considerations. Wherever possible we have chosen pediatric-specific evidence to support our conclusions. One of the major obstacles in device research, particularly airway clearance or maintenance modality, is proper blinding and equipoise.

The lack of scientific rigor, among other issues, has led to a deficiency of high-level evidence. Yet airway maintenance and clearance therapy take a great deal of the respiratory therapist's time. Many clinicians feel that if the patient is producing secretions, we should do something about it. While most studies have focused on the primary outcome of sputum production, it is not clear whether sputum volume is an appropriate indication for or outcome of airway clearance. There is a perception that airway clearance may not help, but it won't hurt either. This attitude can lead to inappropriate orders and inadvertent complications. Many airway-clearance techniques are not benign, particularly if they are not used as intended. That being said, Hess questioned, in a Journal conference summary regarding airway clearance, "Does the lack of evidence mean a lack of benefit?"1 Reasonable evidence is limited in this patient population, and is far from conclusive, so we have taken the liberty of utilizing experience and supportive evidence from adult clinical trials to assist in our quest to clarify the role of airway maintenance and clearance in pediatric acute disease.

The respiratory therapist implements classic airwayclearance techniques to remove secretions from the lungs. These techniques include postural drainage, percussion, chest-wall vibration, and promoting coughing. Newer techniques considered part of chest physical therapy (CPT) include maneuvers to improve the efficacy of cough, such as the forced expiration technique, intrapulmonary percussive ventilation, positive expiratory pressure (PEP) therapy, oscillatory PEP, high-frequency chest compression, and specialized breathing techniques such as autogenic drainage.

Traditional CPT has 4 components: postural drainage, percussion, chest-wall vibration, and coughing. Postural drainage was used in adults as early as 1901, in the treatment of bronchiectasis. ${ }^{1}$ In the 1960s through the 1970 s there was an increase in the use of CPT, a more aggressive adjunct to postural drainage. ${ }^{2}$ Clinicians started to choose this newer form of postural drainage under mounting criticism of intermittent positive-pressure breathing therapy, which was replaced with routine use of CPT. Beginning in the late 1970s, experts in the field began to point to the lack of evidence to support the routine use of CPT in pulmonary disorders such as pneumonia and chronic bronchitis. ${ }^{3}$ Despite a steady stream of criticism, the use of $\mathrm{CPT}$ and other airway-clearance techniques appears to have increased dramatically in the past decade. ${ }^{4-12}$ Conversely, the use of intermittent positive-pressure breathing has diminished drastically.

\section{Postural Drainage}

Postural drainage uses gravity to facilitate movement of secretions from peripheral airways to the larger bronchi where they are more easily expectorated. The clinician 
places the patient in various positions designed to drain specific segments of the lung. If necessary the patient may be supported by rolled towels, blankets, or pillows. There are studies of the multiple variations of this technique., ${ }^{2,3}$ Postural drainage can be performed with or without percussion or vibration. When accompanied by percussion or vibration, each position is maintained for $1-5$ minutes, depending on the severity of the patient's condition. When percussion or vibration is omitted, longer periods of simple postural drainage can be performed.

\section{Percussion}

Percussion is thought to loosen secretions from the bronchial walls. While the patient is in the various postural drainage positions, the clinician percusses the chest wall with a cupped hand, pneumatic or electro-mechanical percussor, or a round sealed applicator. Clinicians should not percuss over bony prominences, the spine, sternum, abdomen, last few ribs, sutured areas, drainage tubes, kidneys, liver, or below the rib cage. The ideal frequency of percussion is unknown; however, some reports recommend a frequency of $5-6 \mathrm{~Hz}$, whereas others recommend slower, rhythmic clapping. ${ }^{3,4}$ Several devices can be used for percussion, including a soft face mask or a commercially designed "palm cup" or pneumatic or electro-mechanical percussor. Clinicians can perform percussion with the patient positioned in various places, including their lap with infants and small children. Appropriate care must be taken to perform the therapy, allowing for the most comfort for the patient and the least amount of risk.

\section{Chest-Wall Vibration}

Vibrations are an additional method of transmitting energy through the chest wall to loosen or move bronchial secretions. Unlike percussion, the clinician's hand or device does not lose contact with the chest wall during the procedure. Vibrations can be performed by placing both hands (one over the other) over the area to be vibrated and tensing and contracting the shoulder and arm muscles while the patient exhales. To prolong exhalation, the patient may be asked to breathe through pursed lips. Like percussion, the ideal frequency is unknown, although some recommend $10-15 \mathrm{~Hz},{ }^{5}$ which can be difficult to achieve manually. It is unclear how well clinicians are able to perform vibrations effectively. Several mechanical vibrators are commercially available. Some models of mechanical percussor or vibrator are appropriate only for the newborn or premature infant, whereas other models provide a stronger vibration appropriate for the larger child. When evaluating such devices, the clinician should consider if the appearance and sound of the device will be frightening and if the amount of force is appropriate for the size of the patient.
All percussion and vibration devices should be cleaned after each use and between patients.

Investigations have been conducted to determine the relative importance of percussion, vibration, and postural drainage. In a study designed to determine the contribution of these maneuvers for mucus clearance there was no demonstration of improvement in mucus clearance from the lung when percussion, vibration, or breathing exercises were added to postural drainage. ${ }^{6}$ The study also showed that forced expiration technique was superior to simple coughing, and when combined with postural drainage was the most effective form of treatment. ${ }^{7}$ This, however, requires a level of cognitive ability not afforded to small children. Other studies have reported that percussion without postural drainage or cough produced minimal change in mucus clearance. Compared to simple postural drainage, chest percussion reduced the amount of sputum mobilized. ${ }^{8}$ Manual self-percussion did not increase the amount of sputum expectorated, compared to simple postural drainage, in a group of patients with cystic fibrosis (CF) ${ }^{8,9}$

The 4 components of traditional CPT are well established and have reimbursement codes and time standards. According to the American Association for Respiratory Care's 2005 Uniform Reporting Manual, the time standard (referenced here as mode) for airway clearance is 1520 min per session. CPT and intrapulmonary percussive ventilation are given a time standard of $20 \mathrm{~min}$, and highfrequency chest compression and PEP therapy are determined to be $15 \mathrm{~min}$. CF patients may take up to an hour to complete a comprehensive airway-clearance session. Acutely ill patients may also require additional time to counterbalance adverse consequences such as hypoxemia from ventilation/perfusion mismatch, atelectasis, or increased oxygen consumption, bronchospasm, hyperventilation, hypoventilation, thermoregulation (in neonates), or tangling or dislodgement of lines and tubes.

\section{Physiologic and Pathophysiologic Considerations}

The primary goal of airway maintenance and clearance therapy is to reduce or eliminate the consequences of obstructing secretions by removing toxic and/or infected material from the bronchioles. Because all of these therapies share the same goal, the term bronchial drainage or hygiene is often employed to describe them collectively. We generalize what is known and written about bronchial hygiene in adults, but the important differences in children cannot be ignored.

\section{Airway Mucus}

The effectiveness of airway maintenance and clearance depends a great deal on the biochemical and biophysical 
characteristics of mucus. The characteristics of adult mucus in health and disease are well understood. In children, however, there is limited knowledge surrounding pediatric airway mucus, with the exception of pediatric CF. Adult mucus contains sialomucins and sulfomucins. Sulfomucins are prevalent at birth, and sialomucins become evident over the first 2 years of life. ${ }^{10}$ Submucosal glands that are responsible for producing most of the body's mucus are $5 \%$ larger in the pediatric airway ${ }^{11}$ than in the adult airway. This may suggest a state of hyperactivity. Mucus viscoelasticity is determined primarily by mucins. The mucin gene products (MUC2, MUC5AC, MUC5B, and MUC7) in infantile pulmonary secretions are different than those in adults. Respiratory tract secretions in children are also more acidic, which may lead to greater viscosity. ${ }^{10}$

\section{Airway pH}

Little is known about the fluid that lines the airway and its role in health and disease. Regarding airway clearance it appears that the $\mathrm{pH}$ of this fluid may play a role in overall lung maintenance. Exhaled-breath condensate is a technique that samples the airway-lining fluid that has advanced our understanding of airway chemistry. Exhaledbreath condensate is obtained noninvasively during exhalation into a condenser. Although mostly water vapor, exhaled-breath condensate contains other constituents such as small molecules, proteins, and even DNA. ${ }^{12}$ The majority of these constituents are aerosolized by turbulent flow in the larger airways. Invasive $\mathrm{pH}$ probe measurements and tracheobronchial-secretion measurements indicate that airway $\mathrm{pH}$ in healthy individuals is mildly alkaline, with a $\mathrm{pH}$ of $7.5-7.8,{ }^{13}$ and correlates nicely with exhaled-breath-condensate $\mathrm{pH} .{ }^{14}$ There has been growing literature regarding changes in exhaled-breath-condensate $\mathrm{pH}$ in acute and chronic respiratory diseases that are characterized, at least in part, by inflammation. Investigators demonstrated that the $\mathrm{pH}$ of exhaled-breath condensate is, in fact, low (acidic) in multiple pulmonary inflammatory diseases, including asthma, COPD, CF, pneumonia, and acute respiratory distress syndrome (ARDS). ${ }^{15-18}$ Some have coined the term acidopneic to describe acidic breath. ${ }^{19}$

The fact that exhaled-breath condensate acidity is the result of airway acidification is supported by general chemistry concepts as well as several lines of evidence. Acids found in exhaled-breath condensate are volatile only when non-ionized/uncharged. The uncharged state exists when these acids are protonated (eg, thus converting from negatively charged acetate to uncharged acetic acid [vinegar] and, likewise, from formate to formic acid). Such protonation occurs in acidic fluid. Increased acids in exhaledbreath condensate are present because of acidification of the source fluid from which the acids are derived. Synergistically, airway-lining fluid acidification traps what would be volatile ammonia $\left(\mathrm{NH}_{3}\right)$ by protonation into the nonvolatile cation ammonium $\left(\mathrm{NH}_{4}{ }^{+}\right)$. Indeed, the $\mathrm{NH}_{3}$ level is low in the exhaled breath during asthma exacerbation..$^{20}$ Thus the findings in exhaled-breath condensate of acidification (acid level high, ammonia level low) are consistent with, and can only be explained by, acidification of the airway-lining fluid at some level of the airway. It is reasonable to consider that inflammation in the airways is associated with acidification. This correlation holds true for other organ systems and pathologic processes.

Gessner and colleagues examined the relationship between exhaled-breath-condensate $\mathrm{pH}$ and severity of lung injury in 35 mechanically ventilated adults. Using the Murray Lung Injury Score, he was able to correlate severity ( $\mathrm{r}$ $=-0.73, P<.001)$ and concluded that exhaled-breathcondensate $\mathrm{pH}$ is a representative marker of acute lung injury caused by or accompanied by pulmonary inflammation. ${ }^{18}$ More recently, Pugin and colleagues found that patients mechanically ventilated for various reasons (eg, ARDS, pneumonia, and after cardiac surgery) had a substantially lower exhaled-breath-condensate $\mathrm{pH}$ than healthy controls. The most interesting finding was not the $\mathrm{pH}$, but the fact that various bacteria from patients with VAP grew better at a slightly acidic $\mathrm{pH}$. This contradicts the statement that a slight acidosis of the airway lining is bacterial static or lung-protective.

Airway inflammation has a central role in the development and progression of acute lung injury. Activation of inflammatory cells, such as neutrophils, eosinophils, and macrophages, has been implicated in the pathophysiology of these diseases. Kostikas et al compared the exhaledbreath-condensate $\mathrm{pH}$ to the number of sputum eosinophils and neutrophils and found tight correlations in diseases such as asthma, COPD, and bronchiectasis. ${ }^{17}$ However, this has not been described in patients with acute lung injury. In fact, the cyclic stretch of alveolar epithelial cells may activate not only inflammatory mediators but also ion channels and pumps. ${ }^{21}$ Given the possible prognostic relationship between exhaled-breath-condensate $\mathrm{pH}$ and clinical symptoms, it is quite plausible that exhaledbreath-condensate $\mathrm{pH}$ can prove useful in various clinical settings, including airway clearance. For example, if exhaled-breath-condensate $\mathrm{pH}$ falls prior to the onset of clinical symptoms, it is probably useful as an early marker, heralding the onset of various inflammatory lung diseases. Specifically, exhaled-breath-condensate $\mathrm{pH}$ could be used as a safe, noninvasive screening or preventive tool for ventilator-associated pneumonia (VAP), ${ }^{21}$ or possibly impaired ciliary motility. Changes in exhaled-breath-condensate $\mathrm{pH}$ might also mark the progression or resolution of disease (eg, alerting clinicians to possible libration from mechanical ventilation). Currently, though, all such notions are hypothetical. 
Table 1. Toxicities of Airway Acidification

\begin{tabular}{|c|c|c|}
\hline First Author & Year & Findings \\
\hline Gaston $^{22}$ & 1997 & $\begin{array}{l}\text { Increased toxicity of reactive nitrogen } \\
\text { and oxygen species }\end{array}$ \\
\hline Ricciardolo $^{23}$ & 1999 & Bronchoconstriction and cough \\
\hline Bevan $^{24}$ & 1994 & Bronchoconstriction and cough \\
\hline Hunt $^{20}$ & 2002 & Epithelial damage and sloughing \\
\hline Holma $^{25}$ & 1977 & $\begin{array}{l}\text { Epithelial damage and sloughing. } \\
\text { Increased mucus viscosity (switch } \\
\text { from sol to gel) with mucus } \\
\text { plugging }\end{array}$ \\
\hline Hunt $^{15}$ & 2000 & $\begin{array}{l}\text { Eosinophilic inflammation and } \\
\text { mediator release }\end{array}$ \\
\hline Low $^{26}$ & 1984 & Decreased mucociliary clearance \\
\hline Holma $^{27,28}$ & 1989 & Decreased mucociliary clearance \\
\hline Nakayama $^{29}$ & 2002 & $\begin{array}{l}\text { Decreased airway epithelial microbial } \\
\text { killing }\end{array}$ \\
\hline Zelenina $^{30}$ & 2003 & $\begin{array}{l}\text { Loss of function of the primary } \\
\text { airway aquaporin at } \mathrm{pH}<7\end{array}$ \\
\hline Horvath $^{31}$ & 2007 & $\begin{array}{l}\text { Inhibition of transepithelial transport } \\
\text { of albuterol }\end{array}$ \\
\hline
\end{tabular}

Low $\mathrm{pH}$ of the airway lining has several adverse effects in the airways that may play a role in airway clearance and maintenance (Table 1).22-31 These negative implications include, but are not limited to, epithelial dysfunction, impaired ciliary motility, ${ }^{32}$ bronchoconstriction, ${ }^{23}$ altered mucus viscosity, inhibition of apoptosis of inflammatory cells, ${ }^{33}$ enhanced bacterial attachment to epithelium, possibly fostering the development of $\mathrm{VAP},{ }^{21}$ and augmented cellular inflammation. ${ }^{15,17}$ Yet we pay little attention to this finding during routine airway clearance and maintenance.

\section{Airway Clearance Mechanisms}

Ciliary movement and cough are the 2 primary airwayclearance mechanisms. Expulsion of mucus requires turbulent flow from the peripheral airways toward the trachea. The airways undergo compression that creates moving choke points or stenosis that catch mucus and facilitate expiratory air flow, propelling the mucus downstream ${ }^{34}$ (Fig. 1). This mechanism requires narrowing of the airway, but complete obstruction will inhibit this transfer. Children, particularly infants, are prone to complete airway obstruction that can lead to atelectasis and the elimination of expiratory flow. This result is particular true in the heterotaxy population.

Infants and children have high chest-wall compliance because they have less musculature, ossification, and stiffness of the ribcage than adults. ${ }^{35}$ They also have a lower pulmonary compliance and greater elasticity than adults, leading to a lower functional residual capacity (FRC), compared to their total lung capacity, which promotes premature airway closure. ${ }^{36}$ The bronchus will collapse as pleu-

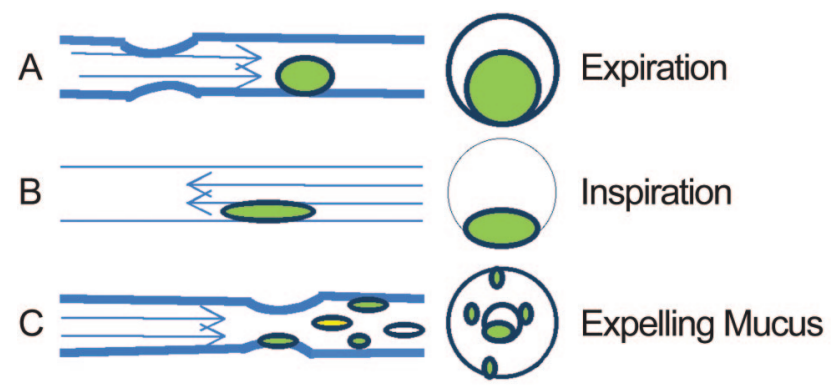

Fig. 1. A: Expiratory flow pushes mucus forward with slight airway compression. B: During inspiration the airways dilate and the mucus spreads. C: The choke point catches the mucus and creates turbulent flow, which aerosolizes the mucus.

ral pressure exceeds intralumen airway pressure. This collapse is avoided by opposing forces that make up the rigidity of the airway structure, specifically smooth muscle in the peripheral airways and cartilage in the central airways. In infants, especially premature infants, the airway cartilage is less developed and more compliant than that of older children and adults. ${ }^{37}$ This increased yielding leads to greater airway collapse at lower changes in pleural and airway pressure. Common neonatal disease states reduce pulmonary compliance and produce bronchial-wall edema, enhancing the risk of airway collapse. The clinical picture of airway collapse often prompts CPT or bronchodilator orders. This airway collapse can be further exaggerated when CPT is performed or bronchodilators administered. Bronchodilators cause decrease in smooth muscle tone, leading to increased collapsibility. This is why continuous positive airway pressure (CPAP) or PEP can be therapeutic in patients with airway collapse, as it tends to improve their FRC and establishes a fundamental airway-clearance mechanism of producing air behind the secretions. Efforts to increase FRC can be valuable tools in the airway-clearance arsenal.

Airway resistance is disproportionately high in children at baseline. Small changes in airway diameter due to edema, secretions, foreign body, or inflammation can lead to drastic changes in resistance. This decrease in air flow limits the child's ability to expel secretions and may contribute to the work of breathing. Furthermore, the upper airway, particularly the nose, can contribute up to $50 \%$ of the airway resistance, which is only compounded by nasal congestion. ${ }^{38}$

Interalveolar pores of Kohn and bronchiolar-alveolar canals of Lambert are compensatory mechanisms that contribute to the aeration of gas-exchange units distal to obstructed airways in older children and adults (Fig. 2). Yet these are missing in infants in which these collaterals are not well developed. This can hinder airway clearance and lead to large areas of atelectasis. 


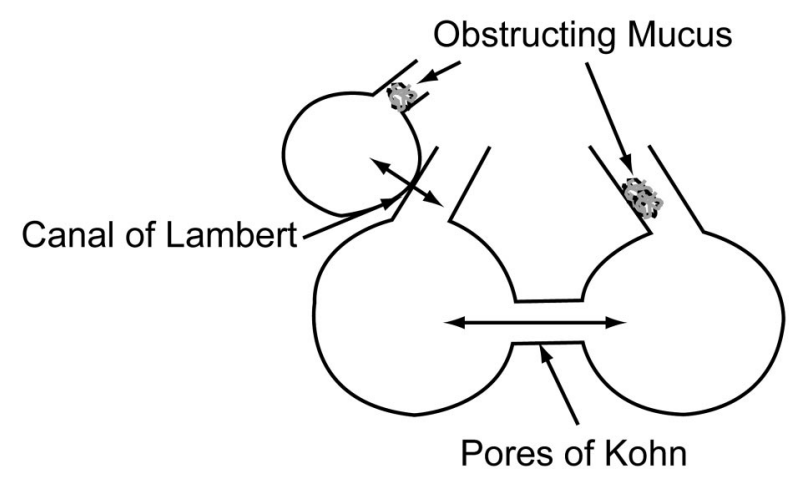

Fig. 2. Alveolar collateral channels in older children and adults facilitate gas exchange around obstructing mucus.

\section{Airway Maintenance}

\section{Humidification}

Optimal humidification results in properly conditioned inspiratory gas. Properly conditioned inspiratory gas maintains ciliary motility, decreases airway hyper-reactivity, and helps keep mucus from undergoing dehydration. Since the introduction of high humidity, at close to body temperature and pressure saturated, via nasal cannula, some practitioners have proactively implemented these devices in the treatment of patients with bronchiolitis. This practice reduces the humidity deficit and potentially lowers airway resistance. McKiernan and colleagues reported results from a retrospective study and showed a decrease in intubation rate, from $23 \%$ to $9 \%$, when nasal cannula was heated and humidified. In the pre-heated high-flow nasal cannula group, $32 \%$ of infants with respiratory syncytial virus were managed on room air or blow-by oxygen. Following the introduction of heated high-flow nasal cannula, all the respiratory syncytial virus infants received humidified gas, some with only humidified air. Bronchiolitics treated with humidified gas may experience a high relative humidity environment that is less likely to tax their natural upper airway. ${ }^{39}$ Suctioning frequency and secretion amount or consistency was, unfortunately, not evaluated.

While humidification of the air creates positive results in airway clearance, this objective is often hard to meet in a hospital setting, due to the dry air, and thus possibly adds stress to a struggling airway. Ideal indoor relative humidity is approximately $40-60 \%$. Achievement of the optimal level in the acute or critical care areas while maintaining the minimal requirement of 6 air changes per hour is difficult. This objective is even harder to meet in the operating room, where the Occupational Safety and Health Administration requires 15 air changes per hour, resulting in an even drier environment. ${ }^{40}$ The winter season compounds the problem. Skoog reported a winter relative in- door humidity level of $16.2 \%,{ }^{41}$ creating an extremely dry atmosphere. When surveyed, most hospital employees and patients rated the air as dry or very dry. ${ }^{41}$ Not surprisingly, in one study $86 \%$ of environment-of-care complaints centered on air dryness. However, regulating humidity is not as easy as it sounds. The aerosolization of contaminated water in hospital humidifiers and/or room humidifiers is a potential source of nosocomial infection. ${ }^{42}$ Specifically, small room humidifiers have been associated with passing Legionella, ${ }^{43}$ are hard to clean, and require between-patient sterilization and the use of sterile or distilled water to prevent cross-contamination. This low-humidity state causes physiologic changes in the upper airway.

The clinician must account for the low humidity in the hospital setting and understand that the low-humidity state causes physiologic changes in the airway. In particular, the nasal turbinates can change frequently in response to dry air. Breathing low-humidity gas triggers blood flow to increase in the highly vascularized nasal mucosa, in order to warm and humidify the inspiratory gas. This action results in swollen turbinates, which can lead to nasal congestion and increase airway resistance, thus escalating a patient's respiratory work load. ${ }^{44}$

The option to breathe and thus humidify orally is virtually nonexistent for our smaller patients, particularly infants who are obligate nose breathers. Dry ambient air will cause the mucus to dry, decreasing its humidity efficiency, and creating a cascade of lower airway drying. During respiratory viral season the outdoor humidity drops further as the air temperature declines. To further complicate the situation, patients with viral upper respiratory tract infections often have humidity deficit due to increase in minute ventilation, decreased oral intake, and fever. When admitted to the hospital, these patients are confined to a room with less than optimal humidity. Treatment of viral upper respiratory infection largely consists of supportive measures such as applying dry medical gases. This presents additional challenges, as these gases boast a relative humidity of less than 5\%. Rarely is the hospital environment discussed or evaluated when delivering care to the pediatric patient, but may place these patients at distinct disadvantage.

Administering dry gas through an artificial airway causes damage to tracheal epithelium within minutes. ${ }^{45,46}$ Care should be taken to quickly provide humidification to patients with artificial airways. Active humidifiers capable of quick warm-up and self-regulation (temperature and water levels) that require few disruptions offer many advantages. In the neonatal population, Todd et al discovered that a higher gas humidity was delivered when the airway temperature probe was positioned outside the incubator. ${ }^{47}$ The study also demonstrated improved inspired humidity with insulating the inspiratory limb in bubble wrap. A commercially available circuit that incorporates this "bubble wrap" concept could prove beneficial. 
Very little evidence exists to guide practitioners in ventilator circuit selection for the pediatric/neonatal population. In 2009, Solomita and colleagues proved the use of heated-wire circuits reduced water-vapor delivery to adult patients ventilated with no bias flow. ${ }^{48}$ However, pediatric settings on a ventilator that utilizes bias flow may produce entirely different results. An important clinical advantage to heated-wire circuits is the reduction in circuit condensate. Condensate left in the circuit offers no benefit and may foster potential harm to patients. An in vivo adult study comparing the use of heated-wire circuits to nonheated-wire circuits in the delivery of humidified gas reported an increase in sputum volume with the usage of non-heated-wire circuits. ${ }^{48}$ Perhaps there was a reduction in retained secretions or just increased rainout in the large airways. Proper humidification effects more than just sputum viscosity.

Temperature importance was validated by Kilgour et al, in sheep. Kilgour showed that a reduction in inspired gas temperature of just $3^{\circ} \mathrm{C}$ reduced both ciliary beat frequency and mucociliary transport velocity. This reduction proceeded quickly to complete cessation. Complete cessation occurred much quicker at a temperature of $30^{\circ} \mathrm{C}, 46$ in which most heat-and-moisture exchangers (HMEs) perform. Proper heating and humidification of inspiratory gas keeps the mucociliary ladder moving at a natural pace.

Active humidification has become the neonatal and pediatric standard, because HME can increase airway resistance and add an unacceptable amount of mechanical dead space. Further, endotracheal tube (ETT) leaks promote loss of humidity to the atmosphere, resulting in less exhaled gas to the HME, reducing its efficiency. When utilizing low-tidal-volume (low- $\mathrm{V}_{\mathrm{T}}$ ) strategies, keeping dead space to a minimum is vital. Increased resistance through an HME can also create or enhance patient/ventilator asynchrony. A 2004 Cochrane review revealed only 3 studies that compared active humidification to HME in the neonatal/pediatric population. While the studies reviewed were far from conclusive, the risk/benefit ratio leads most facilities to employ active humidification for smaller patients. The lack of efficient HMEs for smaller patients seems to also guide this practice. ${ }^{49}$

\section{Airway Suctioning}

The practice of suctioning assists clinicians in obtaining the main goal of all bronchial hygiene, a patent airway, and this remains the most common procedure performed in neonatal and pediatric intensive care units (ICUs). ${ }^{50}$ Instructors teach the "dos and don'ts" of suctioning as some of the first words of wisdom imparted to new therapists. Much pride is derived from a clinician's ability to suction an airway without an adverse event. Unfortunately, this pride has not produced convincing evidence that would otherwise guide safe practice. In prevention of artificialairway occlusion, suctioning is second only to humidification. Frequent suctioning of the upper airway is common in infants with viral respiratory illnesses. Nasal secretions and swollen turbinates increase the nose's contribution to airway resistance. Removing secretions with bulb suctioning reduces resistance, allows for enhanced natural humidification, and decreases the risk of aspiration of virally loaded secretions. There is a lack of evidence on the role of deep suctioning (nasal pharyngeal or nasal tracheal) in viral processes. Increased nasal swelling and epistaxis are common traumatic results of deep suctioning. Thus, the routine practice of deep suctioning should probably play a limited role in the management of pediatric viral illnesses.

\section{Endotracheal Tube Suctioning}

The mere presence of an ETT impairs the cough reflex and may increase mucus production. The smarter suctioning approach consists of suctioning only when a clinical indication arises, not on a scheduled basis. ${ }^{51}$ In the neonatal population, limitation of pre-oxygenation to $10-20 \%$ above baseline $\mathrm{F}_{\mathrm{IO}_{2}}$ is often recommended. ${ }^{51}$ When developing standards for tracheal suctioning, healthcare providers should address catheter size, duration of suctioning, suctioning pressure, deep versus shallow technique, open versus closed technique, saline instillation, lung pathology, and ventilation mode.

\section{Suctioning Preparation}

In preparation for suctioning, selection of an appropriate catheter size is important. A smaller catheter provides more protection to the patient than does a lower suction pressure. ${ }^{52,53}$ Catheter size is, unfortunately, not reported in all studies. In a small study of 17 infants, a catheter-to-ETT diameter ratio of 0.7 proved most effective without increasing the incidence of adverse outcomes. ${ }^{53}$ According to Argent and colleagues, a smaller catheter and a higher suction pressure produced volume-loss equal to that of a larger catheter and a lower suction pressure..$^{53}$ This brings into question the common practice of setting the suction strength based on the patient population rather than the catheter size. In 30 neonates, the use of a 6 French catheter and a suction pressure of $-200 \mathrm{~mm} \mathrm{Hg}$ (which is considerably greater suction pressure than is currently recommended in the United States) did not produce important adverse effects. In that study, Hollering et al limited suctioning time to 6 seconds. ${ }^{54}$ Pulmonary volume loss during suctioning is dependent on the patient's lung compliance, the suctioning pressure applied, the catheter-to-ETT diameter ratio, and the suctioning time. 


\section{Ventilation Mode During Suctioning}

The ventilation mode markedly affects $\mathrm{V}_{\mathrm{T}}$ during closed suctioning. In time-cycled pressure-limited ventilation, $\mathrm{V}_{\mathrm{T}}$ variation occurs during the suctioning procedure..$^{51}$ In contrast, a bench study of adaptive pressure ventilation found a $\mathrm{V}_{\mathrm{T}}$ increase from $6 \mathrm{~mL}$ to $20-26 \mathrm{~mL}$ after suctioning. ${ }^{55}$ The ventilator then took $8-12$ seconds to titrate the inspiratory pressure level back to the pre-suctioning $\mathrm{V}_{\mathrm{T}}{ }^{55}$ That post-suctioning pressure increase might cause pulmonary overdistention and volutrauma lung injury. Patients with secretions to aspirate may not experience that degree of resistance or compliance change, but potential risk exists. During closed suctioning in a time-cycled pressure-limited mode, the pressure variations within the ventilator circuit were minimal. However, the mean tracheal pressure changed as much as $115 \mathrm{~cm} \mathrm{H}_{2} \mathrm{O}$. The balancing of suctioning variables should achieve secretion removal while minimizing adverse effects.

\section{Open Versus Closed Suctioning}

Research supports the use of closed-system suctioning. In closed-system suctioning, an increase in catheter size and suction pressure increases lung-volume loss. In open suctioning, volume loss is independent of catheter size. ${ }^{56}$ This may be explained by the probable presence of turbulent flow between the ETT and suction catheter during closed suctioning. ${ }^{52}$ The concept that closed suctioning is better because it prevents volume loss may be incorrect. As soon as the catheter is inserted into the airway, lungvolume loss begins. However, the potential benefits of closed suctioning include continued delivery of oxygen, supportive positive pressure, lower risk of nosocomial infection, and reduced staff exposure.

To prevent volume loss, one should limit the overall suctioning procedure time, not just the actual suctioning time. A study of 200 neonates who weighed $<1,000 \mathrm{~g}$ found twice the recovery time with open suctioning versus closed suctioning. ${ }^{57}$ In a smaller pediatric study the results were the same, indicating benefits from closed suctioning. In neonates receiving high-frequency oscillatory ventilation (HFOV), closed versus open suctioning produced essentially equal drops in saturation and heart rate, but recovery time from those drops was significantly longer in the open-suctioning group. Not surprisingly, open suctioning produced a greater lung-volume loss. ${ }^{56}$ Note, however, that 4 of the $10 \mathrm{HFOV}$ patients were receiving muscle relaxants, and those paralyzed patients had the longest recovery times. ${ }^{53}$ This could correlate to the fact that paralyzed patients are often sicker. Closed-system suctioning recovery spontaneously occurred in the non-paralyzed patients on HFOV, in approximately one minute. ${ }^{58}$
This phenomenon does not necessarily apply to spontaneously breathing patients on conventional ventilation in the active phase of weaning. Respiratory rate, $\mathrm{V}_{\mathrm{T}}$, and ratio of $\mathrm{V}_{\mathrm{T}}$ to respiratory rate significantly worsened after closed suctioning, and recovery time was longer in the muscle-relaxed patients. These deteriorations caused patients who previously met the extubation criterion to fall below the extubation threshold. The timing of suctioning should be carefully considered when evaluating patients for extubation. Potential for increased atelectasis and respiratory distress may arise from the common practice of suctioning prior to extubation. ${ }^{59}$ The use of recruitment maneuvers with an anesthesia bag after suctioning did not increase dynamic compliance. ${ }^{60}$ Current evidence suggests no benefit to routine post-suctioning recruitment maneuvers.

\section{Saline Instillation}

Saline instillation prior to suctioning remains a controversial topic in pediatrics, particularly with neonates. Catheter insertion alone may dislodge thousands of bacteria; a flush of saline increases this and potentially distributes them distally into the lung, fostering the concern that routine saline instillation may increase the incidence of VAP. In contrast, there is new evidence that the bacteria in the ETT lumen may be eliminated or reduced with routine saline instillation. Additionally, a sedated patient may benefit from a saline-stimulated cough. The patient's cough will always be our strongest ally in airway maintenance. Clearly, suctioning without a cough will only clear the ETT. Caruso's 2009 study of 262 adult patients found a VAP risk reduction of $54 \%$ with routine saline instillation. ${ }^{61}$ A limitation of that study may be that HMEs were utilized to provide humidification, possibly necessitating saline instillation for secretion thinning.

If saline is instilled before suctioning, the clinician must remember the potentially important differences between neonatal and adult airway chemistry, in particular the antimicrobial component of airway mucus in the neonate. A recent study in neonates compared routine use of a lowsodium solution versus routine use of normal saline. The low-sodium solution significantly reduced VAP and chronic lung disease. ${ }^{62}$ In neonates the low-sodium solution may preserve the antimicrobial component of the airway mucus while still enhancing cough and secretion removal. The possible advantages of normal saline for adults and low-sodium saline solution in neonates prompt careful consideration of routine pre-suctioning saline instillation in the pediatric population.

Suctioning is not a benign procedure. Discomfort has been associated with suctioning in the adult population. Facilitated tucking may reduce the pain of suctioning in small infants. This technique requires one caregiver to place the infant in the fetal position while the other is 
suctioning. ${ }^{63}$ Closed suctioning with appropriate catheter size provides shorter recovery times, less pulmonary volume loss, and decreased circuit disconnections. Pressure limits in adaptive pressure ventilation should be set carefully to avoid volutrauma after suctioning. Consider not utilizing adaptive pressure ventilation during and after inline suctioning. Suctioning solution instillation may be beneficial; however, careful consideration of composition, timing, and volume should occur.

\section{Support of Normal Airway Clearance}

In intubated pediatric patients the natural airway maintenance and clearance defenses have been impaired. ${ }^{64}$ An effort to restore these natural defenses offers benefits with much less risk of infection or harm. Restoring the natural isothermic boundary is accomplished with proper conditioning of dry inspiratory gas while the natural airway cannot. Inappropriate inspired gas temperature impairs the mucociliary ladder. Eliminating paralytics and minimizing sedation helps restore spontaneous breathing and natural reflexes. Allowing the patient to spontaneously breathe creates more negative intrathoracic pressure, ${ }^{65}$ which assists in maintaining small-airway diameter and encourages more uniform ventilation. Negative intrathoracic pressure may assist in collateral ventilation around secretions, however few the channels. Effective cough is based on a large breath (increased FRC) prior to a forceful expiration. The forceful expiration is preceded by glottic closure, allowing for pressure build. If the glottis is stented open by an ETT, this pressure buildup is prevented. ${ }^{65} \mathrm{~A}$ clinician-initiated breath-hold may assist with cough preparation.

Sedated or muscularly weak patients may not have the diaphragm strength to take a large enough breath or the abdominal muscle strength to produce sufficient flow for an effective cough. Tussive or extrathoracic squeezes may be beneficial in these patients. The cartilaginous rib cage of an infant allows for a more complete tussive squeeze. However, if during a tussive squeeze the positive pleural pressure exceeds that of the airway pressure, the airway may collapse. Maintaining FRC with positive airway pressure could assist in maintaining airway caliber. During airway peristalsis the airway becomes narrowed at the point of the mucus. This builds a large back-pressure rather quickly. The mucus is then propelled out of the airway. Relaxing airway smooth muscle with bronchodilation may reduce the effectiveness of airway peristalsis for mucus propulsion.

\section{Airway Alkalization}

Returning the airway to a normal $\mathrm{pH}$ may be beneficial. Airway alkalization, such as with phosphorus-buffered saline, sodium bicarbonate, or glycine, may increase ciliary beat, reduce exhaled nitric oxide (a marker of inflamma- tion), ${ }^{66}$ increase mucociliary clearance, improve the uptake of albuterol, ${ }^{31}$ decrease viscosity, reduce VAP in mechanically ventilated ${ }^{21}$ patients, and decrease epithelial damage. However, such notions are pure speculation. Tracheal instillation of bicarbonate is occasionally practiced to attempt to thin the airway mucus ${ }^{67,68}$ by altering the $\mathrm{pH}$ of the secretions. There are very few identifiable references. In our institution, one-quarter-strength use of standard $\mathrm{HCO}_{3} 8.4 \%$ is instilled in $1-2 \mathrm{~mL}$ volumes intratracheally as a mucolytic. Scant data support or oppose its use, but it is reportedly anecdotally successful and safe.

\section{Turning and Positioning}

Alterations in position serve to redistribute ventilation, aid in gravitational movement of secretions toward the large airways, and can foster gas-liquid pumping. ${ }^{34}$ The benefits of frequent turning are often masked by patient decompensation during and after positioning. Increased perfusion and decreased ventilation to the dependent lung is more pronounced in small patients. Their high chestwall compliance can increase the difficulty of expanding the dependent lung. The chest wall is also more difficult to stabilize under gravitational pressure. This same mechanism, however, allows for enhanced ventilation to the lung positioned up. Secretion removal in the non-dependent lung is supported by increased lung recruitment, allowing for larger expiratory volume and faster flow. Small airway caliber in the lung positioned uppermost is also increased. Gravity can then assist in moving secretions through larger airways conducting higher flows. ${ }^{34}$

\section{Assessing the Need for Airway Clearance}

The presumed effectiveness of airway-clearance techniques may be based more on tradition and anecdotal report than scientific evidence. Airway clearance continues to be used excessively and on patients in whom it is contraindicated. The reason lies in the scant literature that exists identifying objective measurements to determine if a pediatric patient needs airway clearance. To gain a better understanding, we looked at the $\mathrm{CF}$ literature. $\mathrm{CF}$ is the best disease to review because $\mathrm{CF}$ involves mucociliary transport dysfunction. The majority of studies performed have used sputum production as the objective measurement. The American Association for Respiratory Care clinical practice guidelines on postural drainage ${ }^{69}$ define "difficulty clearing secretions" as a sputum production greater than $25-30 \mathrm{~mL}$ per day. Quantifying sputum production in children can be difficult, because the volume is less and harder to obtain. Thus, quantifying sputum production is more of a guess and may falsely estimate the need for airway clearance. 


\section{Adventitious Breath Sounds}

Breath sounds are a primary assessment tool in determining the need for airway clearance. Da Silva et al found, in a study of 45 children $<1$ year old, that adventitious breath sounds and sputum production had the highest positive predictive value for insufficient airway clearance. ${ }^{70}$ But does the presence of adventitious breath sounds indicate that the patient is getting worse? Not necessarily. Breath sounds can start diminished and progress to rhonchi after intervention, which could indicate that the mucus has moved from the distal airways to the proximal airways. ${ }^{71}$

A common breath sound heard in children with bronchiolitis is wheezing, which is probably caused by increased resistance to air flow from secretions and/or inflamed airways; yet studies have not revealed that additional airway clearance such as CPT is beneficial. Schechter et al suggested that efficacy studies of airway-clearance techniques in infants and children have been underpowered and otherwise methodically suboptimal. ${ }^{72}$ While it doesn't appear that there is a single indicator for airway clearance, breath sounds may be our best tool.

\section{Gas Exchange}

Gas exchange is a well established tool to evaluate the patient's overall respiratory/metabolic status, but could it assist in determining the need for airway clearance? At times gas exchange may be impaired, indicating a need for airway clearance. Obstructed airways could impair ventilation/perfusion matching. $\mathrm{P}_{\mathrm{aO}} / \mathrm{F}_{\mathrm{IO}_{2}}$ quantifies oxygenation impairment and may help determine the benefits of airway-clearance therapies. The problem with this method is that it requires invasive sampling of arterial blood. However, the relationship of $\mathrm{S}_{\mathrm{pO}_{2}}$ to $\mathrm{F}_{\mathrm{IO}_{2}}$ was recently determined to be a potentially good noninvasive alternative. Tripathi et all found a correlation between $\mathrm{P}_{\mathrm{aO}_{2}} / \mathrm{F}_{\mathrm{IO}_{2}}$ and

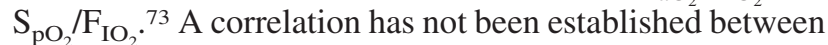
$\mathrm{S}_{\mathrm{pO}_{2}} / \mathrm{F}_{\mathrm{IO}_{2}}$ and the need for airway clearance, but there might be benefit to using $\mathrm{S}_{\mathrm{pO}_{2}} / \mathrm{F}_{\mathrm{IO}_{2}}$ for determining the need for or outcome of a particular airway-clearance technique.

\section{Chest Radiograph}

Chest radiograph may assist the clinical assessment by quantifying the severity of airway-clearance dysfunction. Atelectasis has myriad causes, including bronchial obstruction and extrinsic compression. Most atelectasis is subsegmental in extent and often radiates from the hila or just above the diaphragm. Segments, lobes, and entire lungs may be collapsed, or atelectatic from mucus plugs. This loss of volume may shift fissures toward the area of atelectasis, or cause mediastinal shift toward the affected side.
When mucus is difficult to clear from the airways, it may lead to obstruction. Radiograph may show nonspecific findings of airways disease with peribronchial thickening, atelectasis, and air-trapping. In chronically obstructed patients there may be finger-like mucoid impaction of the airways and abnormal airway dilation (bronchiectasis). Marked hyperinflation is seen in some.

\section{Unique Considerations in Infants and Children}

\section{Gastroesophageal Reflux}

CPT has emerged as the standard airway clearance therapy in the treatment of small patients. CPT increases intrathoracic pressure and can significantly increase abdominal pressure, possibly leading to episodes of gastroesophageal reflux, by compressing the stomach. ${ }^{74}$ The infant's natural defense mechanisms against gastroesophageal reflux are weakened during CPT. Repeat episodes of acid reflux causes esophageal-tissue inflammation, with associated dampening of vagal reflexes. There is a vicious circle of lower-esophageal-sphincter relaxation and more gastroesophageal reflux. Modifying CPT by excluding head-down positions may decrease the number of reflux episodes. ${ }^{75}$ During modified CPT, infants are more likely to remain calm. Keeping the infant calm can decrease intra-abdominal pressure produced by crying. Reflux episodes, as measured with a $\mathrm{pH}$ probe reading of $<4$, occurred most often during crying..$^{75}$ Button and colleagues reported no differences in heart rate or oxygen saturation during reflux episodes, ${ }^{75}$ which illustrates what some call silent aspiration. $\mathrm{pH}$ probe monitoring cannot detect whether reflux contents reach the airways. During CPT on small infants, the clinician should utilize a modified technique, even though it may not lead to the best postural drainage. Any airway-clearance modality that causes crying may encourage gastroesophageal reflux.

\section{Neonates and Premature Infants}

The neonatal patient has a compliant chest wall, few to no collateral airways, smaller airway caliber, poor airway stability, and lower FRC. These physiologic differences hinder airway maintenance and clearance. Neonates' very small airways are subject to closure, especially with application of increased pleural pressure. The term "closing capacity" refers to the volume of gas present in the lungs when the small airways begin to collapse. ${ }^{76}$ In infants, closing capacity exceeds FRC. Neonates struggle to maintain FRC and most often breathe well below closing capacity. Neonates need provider-enhanced small-airway stabilization. Nasal CPAP has many well researched benefits in neonates. Nasal CPAP stabilizes the small airways and maintains FRC, which may restore balance to the muco- 
ciliary ladder. ${ }^{77}$ Nasal CPAP may open airways and allow gas to move beyond secretions and to expel them. CPT often increases pleural pressure and may collapse underdeveloped airways, so the lung units fed by these small airways cannot be recruited by collateral channels. Pathology examination of canine lungs immediately after CPT revealed large atelectatic areas adjacent to the chest wall where CPT was performed. ${ }^{78}$ Proper location of CPT is difficult because of the relatively large abdominal size of neonates. Increases in cerebral blood flow during CPT increase the frequency and severity of intraventricular hemorrhage and the risk of rib fractures. ${ }^{79}$ A minute amount of mucus can create a large increase in airway resistance, which decreases air flow and can prevent gas from expelling secretions. Without expiratory gas moving against it, the mucus becomes trapped. Intermittent or continual CPAP, if tolerated, may benefit neonates by increasing FRC and stabilizing small airways for mucus expulsion. ${ }^{34}$ External thoracic maneuvers combined with appropriate back-pressure can allow for sufficient expiratory flow without complete airway closure. Neonatal chest manipulation is not without risk and requires a high level of expertise. ${ }^{34}$

\section{Behavioral Issues}

When missing the key component of cooperation, airway clearance becomes much more difficult. The potential for harm during airway-clearance modalities increases as transpulmonary pressure swings increase. ${ }^{34}$ When forceful crying occurs during airway clearance, these swings create an environment suitable for lung damage. All efforts to decrease crying, such as facilitated tucking or modified CPT, should be incorporated. In modalities that administer pressure to aid airway clearance, less pressure should be administered to a non-cooperative child. For older patients a multidisciplinary approach can increase airway clearance quantity and quality by $50 \% .{ }^{80}$ This approach, utilized by Ernst et al, involves allowing for patient selection of airwayclearance protocol, creating a reward system for the patient, and scheduling priority given to airway clearance. ${ }^{80}$

\section{Airway Clearance Therapies in the Acute Setting}

Airway-clearance methods are dependent on the disease process. The question arises as to what is appropriate airway clearance in an acute disease process? The use of the appropriate airway-clearance therapy in the acute setting appears to depend on the patient condition and physician preference. The common thought process with most pediatric clinicians is that "it cannot hurt, maybe it can help," but is this actually true? Studies have shown that airway clearance therapy is associated with decreased oxygen saturation, gastroesophageal reflux, fractured ribs, raised intracranial pressure, and even brain injury. ${ }^{81}$ Selection of a best technique is currently more of an art than a science, and depends greatly on the patient's underlying condition, level of functioning and understanding, and ability and willingness to perform the technique and integrate it into normal daily routines. ${ }^{82}$

\section{Cystic Fibrosis}

Airway dysfunction begins during the first year of life, with the earliest pathologic change being thickened mucus and plugging of the submucosal gland ducts in the large airways. ${ }^{83}$ Goblet cells and submucosal glands are the predominant secretory structures of normal airways. In the CF patient there is an increased number of goblet cells and hypertrophy of submucosal glands, which leads to an increase in secretions and sputum production. Airway secretions are relatively dehydrated and viscous. Thick and viscid mucus is such a common feature that at one time the disease was referred to as "mucoviscidosis." 84

Mucociliary clearance is variable in $\mathrm{CF}$, with some patients having severe impairment, whereas others have normal clearance. The reduction in clearance is believed to be caused by the increased volume of respiratory secretions and the abnormally thick mucus. Studies have shown the cilia from CF patients to be normal, although chronic inflammation may result in a loss of ciliated cells. ${ }^{85}$

Airway-clearance techniques are used to assist in the removal of bronchial secretions and are recommended at the first indication of lung involvement. Patients with minimal symptoms may require only one treatment session per day, whereas others with a greater volume of thick secretions may need 3 or more sessions per day. For over 30 years, postural drainage, manual or mechanical percussion, vibration, and assisted coughing have proven to be beneficial in removing the secretions of CF patients. Physical activity and exercise programs have been shown to augment airway clearance.

$\mathrm{CF}$ is considered the cornerstone disease process for secretion clearance. Yet conclusive data are lacking as to the best airway-clearance techniques. In November of 2006 the Pulmonary Therapies Committee began preliminary discussions on the establishment of guidelines for the clinician on the use of best adjunctive therapy for the $\mathrm{CF}$ patient. The search of the literature by the group located a total of 443 citations; all but 13 were excluded, for the following reasons: did not report a review question, did not report a clinical trial, or did not contain original data. The group chose to look at the actual amount of sputum produced. After evaluating these studies, they concluded that no airway-clearance technique has proven to be superior to another. There is scant evidence for $\mathrm{CF}$ in regards to airway-clearance techniques for infants, though the committee suggests starting airway-clearance techniques as 
Table 2. Airway-Clearance Treatments for Asthma

\begin{tabular}{|c|c|c|c|c|}
\hline Treatment & $\begin{array}{l}\text { First } \\
\text { Author }\end{array}$ & Year & Measurements & Efficacy \\
\hline Flutter & Girard $^{89}$ & 1994 & $\begin{array}{l}\mathrm{FEV}_{1} \text {, forced vital capacity, peak } \\
\text { expiratory flow }\end{array}$ & Effective \\
\hline Heliox $(70 / 30)$ vs oxygen $(30 \%)$ & Kass $^{93}$ & 1999 & $\begin{array}{l}\text { Peak expiratory flow, heart rate, respiratory } \\
\text { rate, blood pressure, dyspnea score }\end{array}$ & Effective \\
\hline Chest physical therapy & Asher $^{88}$ & 1990 & Change in pulmonary function & Not effective \\
\hline
\end{tabular}

early as a few months old so that the parents can begin making this part of their daily routine. ${ }^{86}$

Since there is scant evidence from infants and pediatric patients with $\mathrm{CF}$, how do we choose the appropriate therapy for the acute phase of the disease process? The management of patients during their non-acute phase offers a guide. The Pulmonary Therapies Committee for the adult population investigated the amount of sputum produced to determine the effect of airway clearance. The therapy utilized in the acute phase must be evaluated on a case-bycase basis. Every airway-clearance technique has benefits and risks that the clinician must be aware of. Postural drainage and percussion, intrapulmonary percussive ventilation, and high-frequency chest-wall compressions have all proved effective in treating hospitalized CF patients, ${ }^{87}$ but they have also proven harmful. The clinician must remember, "first, do no harm."

\section{Asthma}

Patients who suffer from asthma are at risk for inhibited airway clearance because their airways are narrowed by bronchospasm and/or inflammation. During an exacerbation, fatigue can lead to a weakened cough. Diaphragm compression from hyperinflation limits the cough mechanism. In acute asthma there appears to be no benefit from CPT. The concern would be that you could increase oxygen demand and also stress a patient who is already stressed. ${ }^{88}$ How then, do we deal with secretion clearance in patients with acute asthma? Some support the cough and respiratory effort or drive by utilizing noninvasive ventilation to limit fatigue, whereas others utilize PEP therapy to prevent distal airway collapse. Although in the out-patient setting, Girard et al studied oscillatory PEP (with the Flutter VRP1) in 20 patients with asthma, mucus hypersecretion, and hypersensitivity to dust mites as a major allergen. The patients were asked to use the device a minimum of 5 times a day for at least 5 min per setting for $30-45$ consecutive days. There was significant improvement in $\mathrm{FEV}_{1}$, forced vital capacity, and peak expiratory flow in 18 of the 20 subjects. 89,90

In 2002 an update from the National Asthma Education and Prevention Program found benefits from heliox in the treatment of asthma exacerbations, especially as an alter- native to intubation. Heliox is a less dense gas: $1 / 7$ th that of air. This gives it the capability to reduce turbulent flow. ${ }^{91}$ This transition allows for improved distribution of ventilation that results in less work of breathing. These characteristics, however, can be a double-edged sword. The advantage of heliox is that it creates laminar flow, which lowers work of breathing associated with high airway resistance, potentially provides better aerosol distribution, which may improve therapeutic effect and outcome..$^{92}$ The laminar flow may be a disadvantage when it comes to airway clearance, because turbulent flow is required to break up and move mucus out of the airways. Another concern with heliox is that it is usually delivered in a cold/dry environment. Helium's thermal conductivity is 6 times that of nitrogen. In patients receiving heliox therapy, the nitrogen balance is often completely replaced with helium. This decreases mucociliary activity, which further hinders airway clearance (Table 2). ${ }^{89,91,93}$

\section{Neuromuscular Disease}

A key factor in secretion clearance is being able to get enough air distal to the mucus. When a neuromuscular patient acquires a viral infection, it leads to increased mucus production and ventilation/perfusion mismatch, which can lead to respiratory fatigue if aggressive pulmonary toilet is not initiated. Bach et al found that improving peak cough flow is the single critical factor in removing an artificial airway-both ETTs and tracheostomy tubes. ${ }^{94}$ Dohna-Schwake et al evaluated 29 pediatric neuromuscular patients for an improvement in peak cough flow after intermittent positive-pressure breathing treatment with assisted coughing, which demonstrated a drastic improvement in peak cough flow. 95

Because of the neuromuscular patient's poor respiratory muscle strength, the airway-clearance method should focus on increasing the amount of air distal to the mucus (increasing FRC) as well as assisting the patient with a cough. This can be effectively accomplished with breathstacking, manually assisted cough, and mechanical insufflation-exsufflation. Mechanical insufflation-exsufflation showed the greatest improvement in peak cough flow. ${ }^{95}$ Assisted cough with a sustained inflation provided by a manual resuscitator bag, followed by tussive squeeze, is effective but requires skilled trained staff (Table 3).96-102 
Table 3. Airway-Clearance Treatments for Patients With Neuromuscular Conditions

\begin{tabular}{|c|c|c|c|c|}
\hline $\begin{array}{l}\text { First } \\
\text { Author }\end{array}$ & Year & Treatment & Measurements & Efficacy \\
\hline Dohna-Schwake ${ }^{96}$ & 2006 & $\begin{array}{l}\text { Intermittent positive-pressure } \\
\text { breathing with assisted cough }\end{array}$ & $\begin{array}{l}\mathrm{FEV}_{1} \text {, peak inspiratory pressure, } \\
\text { peak expiratory pressure, peak } \\
\text { cough flow }\end{array}$ & $\begin{array}{l}\text { Effective } \\
\text { Improved peak cough flow }\end{array}$ \\
\hline Panitch $^{97}$ & 2006 & $\begin{array}{l}\text { Breath-stacking, manually assisted } \\
\text { cough, mechanical insufflation- } \\
\text { exsufflation }\end{array}$ & Peak cough flow & $\begin{array}{l}\text { Effective } \\
\text { Peak cough flow showed the greatest } \\
\text { increase with mechanical } \\
\text { insufflation-exsufflation }\end{array}$ \\
\hline Miske $^{98}$ & 2004 & Mechanical insufflation-exsufflation & $\begin{array}{l}\text { Patient reporting of airway } \\
\text { clearance }\end{array}$ & $\begin{array}{l}\text { Mechanical insufflation-exsufflation } \\
\text { was well tolerated }\end{array}$ \\
\hline Birnkrant ${ }^{99}$ & 1996 & $\begin{array}{l}\text { Intrapulmonary percussive } \\
\text { ventilation }\end{array}$ & $\begin{array}{l}\text { Arterial blood gas analysis and } \\
\text { chest radiograph }\end{array}$ & $\begin{array}{l}\text { Two of the } 4 \text { patients with } \\
\text { neuromuscular disease showed } \\
\text { marked improvement }\end{array}$ \\
\hline Deakins ${ }^{100}$ & 2002 & $\begin{array}{l}\text { Intrapulmonary percussive } \\
\text { ventilation vs chest physical } \\
\text { therapy }\end{array}$ & Chest radiograph & $\begin{array}{l}\text { Unchanged in chest-physical-therapy } \\
\text { group } \\
\text { Improved in intrapulmonary- } \\
\text { percussive-ventilation group }\end{array}$ \\
\hline Toussaint $^{101}$ & 2003 & $\begin{array}{l}\text { Assisted mucus-clearance } \\
\text { techniques, with and without } \\
\text { intrapulmonary percussive } \\
\text { ventilation }\end{array}$ & Secretion weight & $\begin{array}{l}\text { More mucus collected with } \\
\text { intrapulmonary percussive ventilation }\end{array}$ \\
\hline Vianello $^{102}$ & 2005 & $\begin{array}{l}\text { Mechanical insufflation-exsufflation } \\
\text { with chest physical therapy vs } \\
\text { chest physical therapy alone }\end{array}$ & $\begin{array}{l}\text { Treatment failure (need for } \\
\text { intubation or mini-tracheostomy) }\end{array}$ & $\begin{array}{l}\text { Fewer failures in the mechanical } \\
\text { insufflation-exsufflation/chest- } \\
\text { physical-therapy group than in the } \\
\text { chest-physical-therapy-only group }\end{array}$ \\
\hline
\end{tabular}

Mechanical insufflation-exsufflation (eg, with CoughAssist, Philips Respironics, Murrysville, Pennsylvania) benefits airway clearance by providing inspiratory pressure (which gets air distal to the mucus) then fast expiratory flow, which simulates cough. ${ }^{103}$ Streigl et al found that, with an infant lung model with a tracheostomy tube during mechanical insufflation-exsufflation, an insufflation time of $\geq 1$ second is required to achieve equilibration of alveolar pressure to insufflation pressure. They also discovered that longer exsufflation time does not significantly alter maximum expiratory flow. ${ }^{103}$ Vienello et al ${ }^{102}$ found that mechanical insufflation-exsufflation in conjunction with traditional CPT may improve the management of airway secretions.

High-frequency chest-wall compression has not been well studied in the treatment of neuromuscular patients. Plioplys et al ${ }^{104}$ found fewer pneumonias and respiratory-related hospitalizations in 7 quadriplegic cerebral palsy patients.

\section{Bronchiolitis}

Bronchiolitis commonly affects infants up to 24 months of age. It is most commonly caused by a viral infection in the lower respiratory tract, and is characterized by acute inflammation, edema, necrosis of the epithelial cells of the small airways, increased mucus production, and bronchospasm. ${ }^{105} \mathrm{CPT}$ is thought to assist in airway clearance in infants with bronchiolitis. A Cochrane review ${ }^{105}$ of the efficacy and safety of chest physiotherapy in infants less that 24 months with acute bronchiolitis found no improvement in stay, oxygen requirement, or difference in illness severity score. ${ }^{106}$ France's national guidelines recommend a specific type of physiotherapy that combines the increased exhalation technique and assisted cough in the supportive care of bronchiolitis patients. But a multicenter randomized trial with 496 previously healthy hospitalized bronchiolitic patients found that that modified physiotherapy regimen (exhalation technique and assisted cough) did not significantly affect time to recovery ${ }^{107,108}$

\section{Postoperative and Post-Extubation Patients}

A common chest radiograph finding in the postoperative patient is atelectasis, which is associated with morbidity. Pain and sedation following surgery can decrease sigh and cough efforts. In 1982, a randomized study of 
CPT in 44 postoperative pediatric cardiac patients found that CPT failed to prevent atelectasis, compared to no intervention. ${ }^{109} \mathrm{~A}$ recent Cochrane review of CPT (vibration or tapping on the chest) in babies following extubation concluded that there was no clear benefit to periextubation CPT, and no decrease in post-extubation lobar collapse, but there was an overall lower re-intubation rate in those who received CPT. ${ }^{110}$ Flenady et al advised caution when interpreting the possible benefits of CPT; because the number of infants studied was small, the results were not consistent across trials, data on safety was insufficient, and application to current practice may be limited by the age of the studies. ${ }^{110}$

\section{Acute Respiratory Failure}

There is little evidence that airway-clearance therapies in previously healthy children with acute respiratory failure improves their morbidity. Since respiratory disease is the most common diagnosis among acute pediatric patients admitted to the hospital, ${ }^{75}$ unnecessary airway-clearance therapies substantially increase costs to the patient and hospital. To find information on adverse effects from chest physiotherapy and postural drainage we looked as far back as the late 1970s, and found only 2 studies focused on children. ${ }^{111,112}$ A positive effect was never demonstrated, and in one study the CPT group (the CPT included percussion and postural drainage) had a significantly longer duration of fever. ${ }^{113} \mathrm{~A}$ review of CPT in 106 infants on mechanical ventilation found there is not enough evidence to determine whether active CPT was beneficial or harmful..$^{79}$ Nor was there enough evidence to determine if one technique was more beneficial than others in resolving atelectasis and maintaining oxygenation.

\section{Future of Airway Maintenance and Clearance}

Interventions to restore natural balance should be the first step in any airway maintenance program; however, much more research is needed. Clinicians need to be willing to weigh the pros and cons of therapies that may hinder this natural defense. Research will continue to focus on new and novel therapies such as airway alkalization, lowsodium solutions for suctioning, nebulized hypertonic solutions, and proactive airway humidification. A select few will retest theories of yesterday, such as routine CPT, negative-pressure ventilation, and suctioning with or without saline.

The future of airway-clearance techniques will continue to evolve. Our wish, however, should be that these therapies wane if they do not provide clear-cut benefit. If we provide proper maintenance, the need for additional airway clearance (above the patient's own) will be minimized. Some of the most simple devices have made the

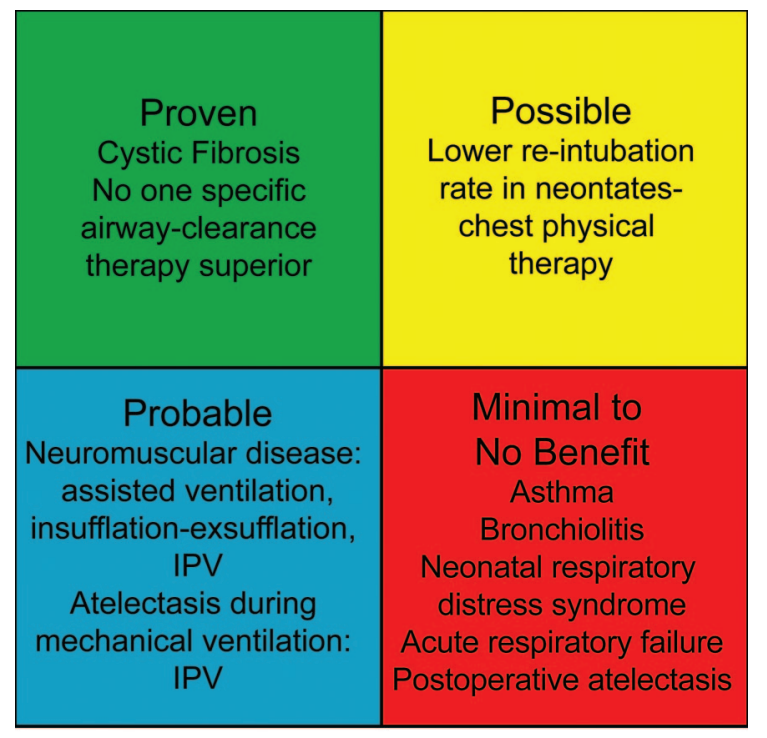

Fig. 3. Benefit from airway-clearance therapies. IPV = intrapulmonary percussive ventilation.

largest impact on airway clearance, and they will continue to do so. We should widely embrace therapies that support the patient's natural airway-clearance mechanisms. This cannot be done without understanding the wide physiologic and pathophysiologic variation before us when caring for the pediatric population. Despite these difficulties and differences, careful research with the intent of "first, do no harm" must continue. Until then we will continue to offer a wide range of airway-clearance techniques to match the diverse patient population.

\section{Summary}

Though there is not enough evidence to definitively evaluate the role of airway-clearance techniques in many acute childhood diseases, it has become routine care for the CF patient. Airway-clearance techniques appear likely to be of benefit in the maintenance or prevention of respiratory-related neuromuscular disease complications and are probably of benefit in treating atelectasis in mechanically ventilated children. Airway-clearance techniques may be of benefit in minimizing re-intubation in neonates, but are of little or no benefit in the treatment of acute asthma, bronchiolitis, or neonatal respiratory distress, or in patients mechanically ventilated for acute respiratory failure, and it is not effective in preventing postoperative atelectasis. Caution should be used, given that the conclusions are based on very limited data (Fig. 3).

One of the staples of respiratory care has been chest physiotherapy. Many new airway-clearance techniques have evolved, but few have demonstrated true efficacy in the pediatric patient population. This practice consumes 
more clinician time and equipment than just about any other therapy in respiratory care, yet it receives the least amount of research. Is it impossible to study, or are we convinced that it improves the health of our patients? Is there equipoise? As our profession matures, we hope that practices like this will not evolve without substantial research to ensure that we are not contributing to the high cost of healthcare or, even more importantly, are not causing harm.

\section{REFERENCES}

1. Hess DR. Airway clearance: physiology, pharmacology, techniques, and practice. Respir Care 2007;52(10):1392-1396.

2. Gaskell D, Webber BA. The Brompton Hospital guide to chest physiotherapy. Oxford: Blackwell Scientific; 1973.

3. Hough A. Physiotherapy in respiratory care: a problem solving approach. London: Chapman \& Hall; 1991.

4. Mellins R. Pulmonary physiotherapy in the pediatric age group. Am Rev Respir Dis 1974;110(2):137-142.

5. Faling L. Chest physical therapy. Philadelphia: Lippincott; 1991: 625-654.

6. Sutton P. Assessment of percussion, vibratory shaking, and breathing exercises in chest physiotherapy. Eur J Respir Dis 1985;66(2): 147-152.

7. Sutton P. Assessment of the forced expiratory technique, postural drainage and directed cough in chest physiotherapy. Eur J Respir Dis 1983;64(1):62-68.

8. Murphy MB CD, FitzGerald M. Chest percussion: help or hindrance to postural drainage. Int Med J 1983;76:189-190.

9. van der Schans C. Effect of manual percussion in tracheobronchial clearance in patients with chronic obstruction and excessive tracheobronchial secretion. Thorax 1986;41:448-452.

10. Rogers DF. Pulmonary mucus: pediatric perspective. Pediatr Pulmonol 2003;36(3):178-188.

11. Jeffrey PK. The development of large and small airways. Am J Respir Crit Care Med 1998;157(5 Pt 2):S174-S180.

12. Montuschi P. Indirect monitoring of lung inflammation. Nat Rev 2002;1(3):238-242.

13. Ricciardolo FL, Gaston B, Hunt J. Acid stress in the pathology of asthma. J Allergy Clin Immunol 2004;113(4):610-619.

14. Paget-Brown AO, Hunt JF, Gaston B. Tracheal aspirate $\mathrm{pH}$ is alkaline in pre-term human infants. Eur Respir J 2007;30(5):840-842.

15. Hunt JF, Fang K, Malik R, Snyder A, Malhotra N, Platts-Mills TA, et al. Endogenous airway acidification. Implications for asthma pathophysiology. Am J Respir Crit Care Med 2000;161(3 Pt 1): 694-699.

16. Tate S, MacGregor G, Davis M, Innes JA, Greening AP. Airways in cystic fibrosis are acidified: detection by exhaled breath condensate. Thorax 2002;57(11):926-929.

17. Kostikas K, Papatheodorou G, Ganas K, Psathakis K, Panagou P, Loukides S. pH in expired breath condensate of patients with inflammatory airway diseases. Am J Respir Crit Care Med 2002; 165(10):1364-1370.

18. Gessner C, Hammerschmidt S, Kuhn H, Seyfarth HJ, Sack U, Engelmann L, et al. Exhaled breath condensate acidification in acute lung injury. Respir Med 2003;97(11):1188-1194.

19. Gaston B, Hunt JF. How acidopneic is my patient? A new question in the pulmonary laboratory. Am J Respir Crit Care Med 2002; 165(10):1349-1350.

20. Hunt J. Exhaled breath condensate: an evolving tool for noninvasive evaluation of lung disease. J Allergy Clin Immunol 2002;110(1):2834.
21. Pugin J, Dunn-Siegrist I, Dufour J, Tissieres P, Charles PE, Comte R. Cyclic stretch of human lung cells induces an acidification and promotes bacterial growth. Am J Respir Cell Mol Biol 2008;38(3):362370 .

22. Gaston B. Expired nitric oxide in pediatric asthma: emissions testing for children? J Pediatr 1997;131(3):343-344.

23. Ricciardolo FLM, Rado V, Fabbri LM, Sterk PJ, Di Maria GU, Geppetti P. Bronchoconstriction induced by citric acid inhalation in guinea pigs: role of tachykinins, bradykinin, and nitric oxide. Am J Respir Crit Care Med 1999;159(2):557-562.

24. Bevan S, Geppetti P. Protons: small stimulants of capsaicin-sensitive sensory nerves. Trends Neurosci 1994;17(12):509-512.

25. Holma B, Lindegren M, Andersen JM. pH effects on ciliomotility and morphology of respiratory mucosa. Arch Environ Health 1977; 32(5):216-226.

26. Low PM, Luk CK, Dulfano MJ, Finch PJ. Ciliary beat frequency of human respiratory tract by different sampling techniques. Am Rev Respir Dis 1984;130(3):497-498.

27. Holma B, Hegg PO. pH- and protein-dependent buffer capacity and viscosity of respiratory mucus. Their interrelationships and influence on health. Sci Total Environ 1989;84:71-82.

28. Holma B. Effects of inhaled acids on airway mucus and its consequences for health. Environ Health Perspect 1989;79:109-113.

29. Nakayama K, Jia YX, Hirai H, Shinkawa M, Yamaya M, Sekizawa $\mathrm{K}$, Sasaki H. Acid stimulation reduces bactericidal activity of surface liquid in cultured human airway epithelial cells. Am J Respir Cell Mol Biol 2002;26(1):105-113.

30. Zelenina M, Bondar AA, Zelenin S, Aperia A. Nickel and extracellular acidification inhibit the water permeability of human aquaporin-3 in lung epithelial cells. J Biol Chem 2003;278(32):30037-30043.

31. Horvath G, Schmid N, Fragoso MA, Schmid A, Conner GE, Salathe $\mathrm{M}$, et al. Epithelial organic cation transporters ensure $\mathrm{pH}$-dependent drug absorption in the airway. Am J Respir Cell Mol Biol 2007;36(1): 53-60.

32. Luk CK, Dulfano MJ. Effect of $\mathrm{pH}$, viscosity and ionic-strength changes on ciliary beating frequency of human bronchial explants. Clin Sci 1983;64(4):449-451.

33. Hammerschmidt S, Kuhn H, Grasenack T, Gessner C, Wirtz H. Apoptosis and necrosis induced by

34. Oberwaldner B. Physiotherapy for airway clearance in paediatrics. Eur Respir J 2000;15(1):196-204.

35. Papastamelos C, Panitch HB, England SE, Allen JL. Developmental changes in chest wall compliance in infancy and early childhood. J Appl Physiol 1995;78(1):179-184.

36. Lai-Fook SJ, Hyatt RE. Effects of age on elastic moduli of human lungs. J Appl Physiol 2000;89(1):163-168.

37. Penn RB, Wolfson MR, Shaffer TH. Developmental differences in tracheal cartilage mechanics. Pediatr Res 1989;26(5):429-433.

38. Hall GL, Hantos Z, Wildhaber JH, Sly PD. Contribution of nasal pathways to low frequency respiratory impedance in infants. Tho$\operatorname{rax} 2002 ; 57(5): 396-399$.

39. McKiernan C, Chua LC, Visintainer PF, Allen H. High flow nasal cannulae therapy in infants with bronchiolitis. J Pediatr 2010;156(4): 634-638.

40. United States Department of Labor, OSHA Directorate of Technical Support and Emergency Management. Anesthetic gases: guidelines for workplace exposures. July 20, 1999. Revised May 18, 2000. http:// www.osha.gov/dts/osta/anestheticgases/index.html. Accessed July 12, 2011.

41. Skoog J. Relative air humidity in hospital wards - user perception and technical consequences. Indoor Build Environ 2006(15):93-97.

42. Chatburn RL, Lough MD, Klinger JD. An in-hospital evaluation of the sonic mist ultrasonic room humidifier. Respir Care 1984;29(9): 893-899. 
43. Zuravleff JJ, Yu VL, Shonnard JW, Rihs JD, Best M. Legionella pneumophila contamination of a hospital humidifier. Demonstration of aerosol transmission and subsequent subclinical infection in exposed guinea pigs. Am Rev Respir Dis 1983;128(4):657-661.

44. Naftali S, Schroter RC, Shiner RJ, Elad D. Transport phenomena in the human nasal cavity: a computational model. Ann Biomed Eng 1998;26(5):831-839.

45. Williams R, Rankin N, Smith T, Galler D, Seakins P. Relationship between the humidity and temperature of inspired gas and the function of the airway mucosa. Crit Care Med 1996;24(11):1920-1929.

46. Kilgour E, Rankin N, Ryan S, Pack R. Mucociliary function deteriorates in the clinical range of inspired air temperature and humidity. Intensive Care Med 2004;30(7):1491-1494.

47. Todd DA, Boyd J, Lloyd J, John E. Inspired gas humidity during mechanical ventilation: effects of humidification chamber, airway temperature probe position and environmental conditions. J Paediatr Child Health 2001;37(5):489-494.

48. Solomita M, Palmer LB, Daroowalla F, Liu J, Miller D, LeBlanc DS, et al. Humidification and secretion volume in mechanically ventilated patients. Respir Care 2009;54(10):1329-1335.

49. Kelly M, Gillies D, Todd DA, Lockwood C. Heated humidification versus heat and moisture exchangers for ventilated adults and children. Cochrane Database Syst Rev 2010;(4):CD004711.

50. Argent AC. Endotracheal suctioning is basic intensive care or is it? Pediatr Res 2009;66(4):364-367.

51. Gardner DL, Shirland L. Evidence-based guideline for suctioning the intubated neonate and infant. Neonatal Netw 2009;28(5):281302.

52. Kiraly NJ, Tingay DG, Mills JF, Morley CJ, Dargaville PA, Copnell $B$. The effects of closed endotracheal suction on ventilation during conventional and high-frequency oscillatory ventilation. Pediatr Res 2009;66(4):400-404.

53. Argent AC, Morrow BM. What does chest physiotherapy do to sick infants and children? Intensive Care Med 2004;30(6):1014-1016.

54. Hoellering AB, Copnell B, Dargaville PA, Mills JF, Morley CJ, Tingay DG. Lung volume and cardiorespiratory changes during open and closed endotracheal suction in ventilated newborn infants. Arch Dis Child Fetal Neonatal Ed 2008;93(6):F436-F441.

55. Kiraly NJ, Tingay DG, Mills JF, Dargaville PA, Copnell B. Volume not guaranteed: closed endotracheal suction compromises ventilation in volume-targeted mode. Neonatology 2011;99(1):78-82.

56. Copnell B, Dargaville PA, Ryan EM, Kiraly NJ, Chin LO, Mills JF, et al. The effect of suction method, catheter size, and suction pressure on lung volume changes during endotracheal suction in piglets. Pediatr Res 2009;66(4):405-410.

57. Kalyn A, Blatz S, Sandra F, Paes B, Bautista C. Closed suctioning of intubated neonates maintains better physiologic stability: a randomized trial. J Perinatol 2003;23(3):218-222.

58. van Veenendaal MB, Miedema M, de Jongh FH, van der Lee JH, Frerichs I, van Kaam AH. Effect of closed endotracheal suction in high-frequency ventilated premature infants measured with electrical impedance tomography. Intensive Care Med 2009;35(12):21302134.

59. Seymour CW, Cross BJ, Cooke CR, Gallop RL, Fuchs BD. Physiologic impact of closed-system endotracheal suctioning in spontaneously breathing patients receiving mechanical ventilation. Respir Care 2009;54(3):367-374.

60. Copnell B. Effect of endotracheal suction on lung dynamics in mechanically-ventilated paediatric patients. Nurs Crit Care 2008; 13(1):54-55.

61. Caruso P, Denari S, Ruiz SA, Demarzo SE, Deheinzelin D. Saline instillation before tracheal suctioning decreases the incidence of ventilator-associated pneumonia. Crit Care Med 2009;37(1):32-38.
62. Christensen RD, Henry E, Baer VL, Hoang N, Snow GL, Rigby G, et al. A low-sodium solution for airway care: results of a multicenter trial. Respir Care 55(12):1680-1685.

63. Helder OK, Latour JM. Endotracheal suctioning: there's more to it than just technical care. Pediatr Crit Care Med 2008;9(5):539-540.

64. Pneumatikos IA, Dragoumanis CK, Bouros DE. Ventilator-associated pneumonia or endotracheal tube-associated pneumonia? An approach to the pathogenesis and preventive strategies emphasizing the importance of endotracheal tube. Anesthesiology 2009;110(3):673-680.

65. Donahue M. "Spare the cough, spoil the airway:" back to the basics in airway clearance. Pediatr Nurs 2002;28(2):107-111.

66. Gaston B, Kelly R, Urban P, Liu L, Henderson EM, Doctor A, et al. Buffering airway acid decreases exhaled nitric oxide in asthma. J Allergy Clin Immunol 2006;118(4):817-822.

67. Rau J. Mucous-controlling, surface-active, and cold and cough agents. In: Respiratory Care Pharmacology. Chicago: Year Book, 1989;144-179.

68. Connolly MA. Mucolytics and the critically ill patient: help or hindrance? AACN Clin Issues 1995;6(2):307-315.

69. American Association for Respiratory Care. Clinical practice guideline: Postural drainage therapy. Respir Care 1991;36(12):1418-1426.

70. da Silva VM, Lopes MV, de Araujo TL, Ciol MA, de Carvalho EC. Clinical indicators of ineffective airway clearance in children with congenital heart disease. J Clin Nurs 2009;18(5):729-736.

71. Hess D. The AARC (American Association for Respiratory Care) clinical practice guidelines. Respir Care 1991;36(12):1398-1401.

72. Schechter MS. Airway clearance applications in infants and children. Respir Care 2007;52(10):1382-1390; discussion 1390-1391.

73. Tripathi RS, Blum JM, Rosenberg AL, Tremper KK. Pulse oximetry saturation to fraction inspired oxygen ratio as a measure of hypoxia under general anesthesia and the influence of positive endexpiratory pressure. J Crit Care 2010;25(3):542; e549-513.

74. Vandenplas Y, Diericx A, Blecker U, Lanciers S, Deneyer M. Esophageal $\mathrm{pH}$ monitoring data during chest physiotherapy. J Pediatr Gastroenterol Nutr 1991;13(1):23-26.

75. Button BM, Heine RG, Catto-Smith AG, Phelan PD, Olinsky A. Chest physiotherapy, gastro-oesophageal reflux, and arousal in infants with cystic fibrosis. Arch Dis Child 2004;89(5):435-439.

76. Oberwaldner B, Zach MS. [Mucous clearing respiratory-physiotherapy in pediatric pneumology]. Schweiz Med Wochenschr 2000; 130(19):711-719. Article in German.

77. Siew ML, Te Pas AB, Wallace MJ, Kitchen MJ, Lewis RA, Fouras A, et al. Positive end-expiratory pressure enhances development of a functional residual capacity in preterm rabbits ventilated from birth. J Appl Physiol 2009;106(5):1487-1493.

78. Zidulka A, Chrome JF, Wight DW, Burnett S, Bonnier L, Fraser R. Clapping or percussion causes atelectasis in dogs and influences gas exchange. J Appl Physiol 1989;66(6):2833-2838.

79. Hough JL, Flenady V, Johnston L, Woodgate PG. Chest physiotherapy for reducing respiratory morbidity in infants requiring ventilatory support. Cochrane Database Syst Rev 2008(3):CD006445.

80. Ernst MM, Wooldridge JL, Conway E, Dressman K, Weiland J, Tucker K, et al. Using quality improvement science to implement a multidisciplinary behavioral intervention targeting pediatric inpatient airway clearance. J Pediatr Psychol 35(1):14-24.

81. Hess DR. Secretion clearance techniques: absence of proof or proof of absence? (editorial) Respir Care 2002;47(7):757-758.

82. Fink JB. Positive pressure techniques for airway clearance. Respir Care 2002;47(7):786-796.

83. Lamb D, Reid L. The tracheobronchial submucosal glands in cystic fibrosis: a qualitative and quantitative histochemical study. Br J Dis Chest 1972;66(4):240-247. 
84. Zuelzer W, Newton W. The pathogenesis of fibrocystic disease of the pancreas: a study of 36 cases with special reference to pulmonary lesions. Pediatrics 1949;4(1):53-69.

85. Katz S, Holsclaw, DS Jr. Ultrastructural features of respiratory cilia in cystic fibrosis. Am J Clin Pathol 1980;73(5):682-685.

86. Flume PA, Robinson KA, O’Sullivan BP, Finder JD, Vender RL, Willey-Courand DB, et al. Cystic fibrosis pulmonary guidelines: airway clearance therapies. Respir Care 2009;54(4):522-537.

87. Varekojis SM, Douce FH, Flucke RL, Filbrun DA, Tice JS, McCoy $\mathrm{KS}$, et al. A comparison of the therapeutic effectiveness of and preference for postural drainage and percussion, intrapulmonary percussive ventilation, and high-frequency chest wall compression in hospitalized cystic fibrosis patients. Respir Care 2003;48(1):24-28.

88. Asher MI, Douglas C, Airy M, Andrews D, Trenholme A. Effects of chest physical therapy on lung function in children recovering from acute severe asthma. Pediatr Pulmonol 1990;9(3):146-151.

89. Girard JP, Terki N. The Flutter VRP1: a new personal pocket therapeutic device used as an adjunct to drug therapy in the management of bronchial asthma. J Investig Allergol Clin Immunol 1994;4(1):23-27.

90. Myers TR. Positive expiratory pressure and oscillatory positive expiratory pressure therapies. Respir Care 2007;52(10):1308-1326; discussion 1327

91. Gupta VK, Cheifetz IM. Heliox administration in the pediatric intensive care unit: an evidence-based review. Pediatr Crit Care Med 2005;6(2):204-211.

92. Anderson M, Svartengren M, Bylin G, Philipson K, Camner P. Deposition in asthmatics of particles inhaled in air or in heliumoxygen. Am Rev Respir Dis 1993;147(3):524-528.

93. Kass JE, Terregino CA. The effect of heliox in acute severe asthma: a randomized controlled trial. Chest 1999;116(2):296-300.

94. Bach JR, Saporito LR. Criteria for extubation and tracheostomy tube removal for patients with ventilatory failure. A different approach to weaning. Chest 1996;110(6):1566-1571.

95. Panitch HB. Respiratory issues in the management of children with neuromuscular disease. Respir Care 2006;51(8):885-893; discussion 894-885.

96. Dohna-Schwake C, Ragette R, Teschler H, Voit T, Mellies U. IPPB-assisted coughing in neuromuscular disorders. Pediatr Pulmonol 2006;41(6):551-557.

97. Panitch HB. Airway clearance in children with neuromuscular weakness. Curr Opin Pediatr. 2006;18(3):277-281.

98. Miske LJ, Hickey EM, Kolb SM, Weiner DJ, Panitch HB. Use of the mechanical in-exsufflator in pediatric patients with neuromuscular disease and impaired cough. Chest 2004;125(4):1406-1412.

99. Birnkrant DJ, Pope JF, Lewarski J, Stegmaier J, Besunder JB. Persistent pulmonary consolidation treated with intrapulmonary percussive ventilation: a preliminary report. Pediatr Pulmonol 1996; 21(4):246-249.
100. Deakins K, Chatburn RL. A comparison of intrapulmonary percussive ventilation and conventional chest physiotherapy for the treatment of atelectasis in the pediatric patient. Respir Care 2002;47(10): 1162-1167.

101. Toussaint M, De Win, Steens M, Soudon P. Effect of intrapulmonary percussive ventilation on mucus clearance in duchenne muscular dystrophy patients: a preliminary report. Respir Care 2003; 48(10):940-947.

102. Vianello A, Corrado A, Arcaro G, Gallan F, Ori C, Minuzzo M, et al. Mechanical insufflation-exsufflation improves outcomes for neuromuscular disease patients with respiratory tract infections. Am J Phys Med Rehabil 2005;84(2):83-88; discussion 89-91.

103. Striegl AM, Redding GJ, Diblasi R, Crotwell D, Salyer J, Carter ER. Use of a lung model to assess mechanical in-exsufflator therapy in infants with tracheostomy. Pediatr Pulmonol 2010 [Epub ahead of print].

104. Plioplys AV. Correspondence on "safety, tolerability, and efficacy of high-frequency chest wall oscillation in pediatric patients with cerebral palsy and neuromuscular diseases: an exploratory randomized controlled trial". J Child Neurol 2010;25(12):1598; author reply 1598.

105. Perrotta C, Ortiz Z, Roque M. Chest physiotherapy for acute bronchiolitis in paediatric patients between 0 and 24 months old. Cochrane Database Syst Rev 2007(1):CD004873.

106. Subcommittee on Diagnosis and Management of Bronchiolitis. Diagnosis and management of bronchiolitis. Pediatrics 2006;118(4): 1774-1793.

107. Bailleux S, Lopes D, Geoffroy A, Josse N, Labrune P, Gajdos V. [What evidence for chest physiotherapy in infants hospitalized for acute viral bronchiolitis?]. Arch Pediatr 2011;18(4):472-475. Article in French.

108. Gajdos V, Katsahian S, Beydon N, Abadie V, de Pontual L, Larrar $S$, et al. Effectiveness of chest physiotherapy in infants hospitalized with acute bronchiolitis: a multicenter, randomized, controlled trial. PLoS Med 2010;7(9):e1000345.

109. Reines HD, Sade RM, Bradford BF, Marshall J. Chest physiotherapy fails to prevent postoperative atelectasis in children after cardiac surgery. Ann Surg 1982;195(4):451-455.

110. Flenady VJ, Gray PH. Chest physiotherapy for preventing morbidity in babies being extubated from mechanical ventilation. Cochrane Database Syst Rev 2002(2):CD000283.

111. Levin AN. [Classification of acute pneumonia in children]. Pediatriia 1978(4):69-70. Article in Russian.

112. Stapleton T. Chest physiotherapy in primary pneumonia. BMJ (Clin Res Ed) 1985;291(6488):143.

113. Britton S, Bejstedt M, Vedin L. Chest physiotherapy in primary pneumonia. BMJ (Clin Res Ed) 1985;290(6483):1703-1704.

\section{Discussion}

Willson: Brian, regarding airway alkalization, you seemed to imply that at least Pseudomonas grows better in an acidic $\mathrm{pH}$, but later you said that maybe acidification is a host defense. Is that a contradiction?

Walsh: When we first found out that the lung is so acidic, we were wonder- ing whether this acidification is actually beneficial. It appears that it's only beneficial when it's extremely acidic; it only appears to kill bacteria when you get down to a $\mathrm{pH}$ of 4.0 or 4.5 . It does the exact opposite at a $\mathrm{pH}$ or 6.5 or 7.0 ; it increases bacterial growth, compared to the normal environment of $\mathrm{pH}$ 7.8. It seems to be kind of a bell-curve effect, where the 6.5 to 7.0 range promotes bacteria growth.
Wiswell: You didn't mention the effects of our old pal acetylcysteine.

Walsh: I was hoping Bruce would cover that. We used to use acetylcysteine a lot. It's slightly acidic compared to 7.8-8.0 lung environment, so it could make things worse. I personally think it's a pretty good mucolytic, but we've gotten away from it mainly because there's a lack of 
evidence. Frankly, I think a lot of therapists think it stinks, and they don't recommend it because they don't want to deal with it. I think that does sometimes drive practice inappropriately.

Dalton: I've used bicarbonate a lot in kids I'm trying to get secretions out of, but I had never really delved into the physiologic reasons of why it might help, so thanks for explaining that. I think something that's coming soon, or is now on the market, is bullets of what would have been known a couple of years ago as perflubron for suctioning. Have you had any experience with that?

Walsh: No, but it intrigues me. If you use a large volume of saline, you can inhibit oxygenation. Some of these patients need lots of lavaging, and perflubron may deliver some oxygen while allowing you to remove more secretions.

Dalton: Dick Martin, at Origin, took that over. He's been a big friend of the ECMO [extracorporeal membrane oxygenation] community. I know he's marketing it, and it' 11 be interesting to see if it works.

Walsh: It helps with debris removal, which we found out when we were doing liquid lung ventilation. It was very effective at removing debris.

Dalton: I used to be a fan of in-line [closed-system] suctioning, but now I don't think it really helps, and I think a lot of times it messes up your airway mechanics more than anything else. In-line suctioning is supposed to decrease VAP, but a lot of the recent literature doesn't make it seem like it does that much good. And if you're doing a recruitment maneuver after either open or closed suctioning, it's actually probably better than what you're describing. I wonder if it really makes that big a difference?

Walsh: A topic we're lecturing on at this year's AARC [American As- sociation for Respiratory Care International Respiratory Congress] is that hand-ventilating kids potentially makes things a lot worse, because hand ventilation is very uncontrolled. Doing recruitment maneuvers after suctioning is interesting, but I would say that it's not the in-line suction catheter vs the open.

It's actually how we ventilate during suctioning. A lot of people are scared to turn up the ventilator knobs during in-line suctioning or shortly after, but they're not scared to squeeze a bag harder, because those pressures are not documented. I have to document the ones I set on the ventilator. Some people use bagging as a "runaround," and we should advocate a protocol that allows the therapist to do post-suctioning recruitment maneuvers, and open versus closed suctioning is probably not going to make a big difference if you do exactly the same thing.

If you do a recruitment maneuver with open suctioning, it's a little bit harder because you have to clamp the ETT to keep them at the maximum inspiration before reconnecting the ventilator. If you reconnect at the wrong time, it can be problematic. I'm a little nervous about clamping, because I've heard of having a hard time getting the clamp off, especially with some of the older metal ones. We use plastic ones now that you can break if you have to. I would rather just use the ventilator, where I can monitor the volumes of those big breaths.

Rubin: Just a bunch of fairly randomly directed comments. Saline suctioning isn't a matter of saline versus no saline, but it's how you put it in there. If you put in saline with the notion that it's going to loosen up secretions and make them easier to suction up, that's great. But if you loosen up secretions and then put a bloody bag on and push it down deep into the airway, you may be causing more problems. So instillation of saline and the immediate aspiration of saline does make some sense-instillation of saline and then deep bagging it into the lung and then putting in a suction catheter down into the tube makes no sense whatsoever. It's technique as much as what you put in there.

Similarly, with perflubron; it was approved long ago as an agent for imaging because it's radiopaque. It is effective for debris mobilization: we've shown that. It's interesting that it has some anti-inflammatory properties, and it also has a very low surface tension, of about $10 \mathrm{dyn} / \mathrm{cm}$, meaning it spreads quickly and then rapidly becomes volatile. I'm interested in seeing some controlled studies, rather than just approval, but it does potentially make sense to use that as opposed to something like saline.

We've also evaluated the $\mathrm{pH}$ dependence of the viscoelastic and transport properties of airway secretions and have not shown significant influence of $\mathrm{pH}$. We've been able to manipulate $\mathrm{pH}$ to some extent, having shown that alters either the rheology or the transportability of secretions. Bicarbonate is incredibly irritating, has minimal effect on the airway secretion rheology, and may cause patients to cough, which could potentially be considered a benefit. But because it's so irritating, it does carry risks, and if you use bicarbonate, I would be cautious about it. I wouldn't recommend it as a way of clearing secretions.

Walsh: Do you think bicarbonate is a phenomenon of the amount of bicarbonate or buffering capacity versus its toxicity to the airway? A lot of people are not using the $8.4 \%$ : they're diluting it down to $2-4 \%$. In my experience, giving it quite frequently, I've had some intensivists who are advocates of using bicarbonate. It seems to be well tolerated.

Rubin: We only looked at the $8.4 \%$, because that's how it comes. I don't know about dilution. It sounds safer, but I have no data. 
Cheifetz: Acknowledging that this may be institution-specific, the responsibility for secretion clearance is often distributed across hospital departments: some responsibility is given to physical therapy, some to nursing, and some to respiratory therapy. Although that approach increases the number of clinicians available to assist with secretion clearance, the overall process tends to be inefficient. In our institution we are working on an initiative to center secretion clearance responsibility with the respiratory therapy program. Of course, that requires additional respiratory therapy resources, which in turn requires strong administrative support. Do you have data on the optimal operational approach for a secretion-clearance program? If not, what are your personal views? What advice would you offer on how to implement a secretion/airway-clearance program?

Walsh: The evidence is all over the place in support of its use, and I'm a firm believe that if you do something good, you should probably stick with it. From an administrative standpoint, all of these airway-clearance modalities are an education nightmare, because the therapists have to know the ins and outs of each one. It appears, at least in the CF population, that adherence is vitally important. We spend most of our time figuring out what device they'll use. So it is hard for the respiratory therapist.

I've gone to 3 institutions now, and they do airway clearance in 3 different ways. In one institution we didn't do it at all: it was physical therapy and nursing, because the director didn't advocate for it because of a lack of evidence. Based on the evidence, I worry that there's a lot of inappropriate therapy, because we do a lot CPT, and developing a team may only foster that. Now that I'm an administrator; I find that we can get a lot of revenue for it. Maybe that's something we shouldn't look at, but it may keep administra- tors advocating for less CPT and those types of things.

I think we do a lot of inappropriate therapy, and most of it is probably not beneficial, and we forget the basics. I want to emphasize that we actually know very little about the lung environment. I think we're learning more each day, but it's something I wanted to bring back up. The oldies but goodies. Bicarbonate, mucolytics, and those types of things: are they actually helpful?

Cheifetz: I agree with you. If clinicians used only therapies that have been proven to work, we would be back to the basics. Eliminating expensive and unproven therapies could help with the financial case for the additional resources needed for a respiratory-based program. The key would be demonstrating a shorter duration of ventilation, shorter ICU and/or hospital stay, and limiting equipment and medication expenses. However, I am not aware of data that convincingly address these complex issues in pediatrics. We are conducting a study to find some of the answers.

Walsh: Depending on your department and your therapist relationship to physicians, sometimes they'll order therapies just because they want you to see the patient more frequently. They don't believe there's benefit from airway clearance, and they want you to go in there every 2 hours and check on the patient, so they'll order CPT because they think CPT won't hurt. I think that's the wrong way to do it, but it's something I've come across a couple of times, where the physician says, "Yeah, I don't really think CPT helps, but your being in that room does."

Wiswell: Brian, our anesthesiology colleagues commonly use some systemic drugs, such as glycopyrrolate, to try to dry up lung secretions in the operating room. As everybody knows, when you ventilate a child and have an ETT in place, within hours to days you'll have an incredible amount of secretions, which drives nurses, therapists, and physicians crazy. Many of our staff push us to use such drugs, which are typically anticholinergic agents, which can have systemic adverse effects, including tachycardia and hypertension. I have yet to see any kind of randomized controlled trial on their routine use in the ICU.

Walsh: I've seen that as well-patients coming back from the operating room a couple hours after they've received a large amount of relative humidity, and they start coming up with lots of secretions. And in the operating rooms they tend to use HMEs, though not with smaller kids because of the dead space, so they're giving them dry gas and using those agents you mentioned. Sometimes it's a nightmare for the therapists, who have to check on those patients much more frequently and try to get them extubated sooner, because they come back with very thick secretions. Probably it's the lack of humidity.

Rogers:* I want to comment about closed suctioning. Coming from an HFOV background, I used to advocate closed suctioning to prevent losing lung volume. However, David Tingay's team at Murdoch Children's Research Institute in Australia published a series of articles on closed versus open suctioning. ${ }^{1-3}$ They found significantly better secretion clearance with open suctioning, because the airway collapse squeezes the secretions out to the larger airways where the suction catheter can pull them out. Perhaps at the bedside the clinician should decide what method should be used, with the primary goal of secretion removal versus lung-volume retention, and occasionally do open suctioning.

\footnotetext{
* Mark Rogers RRT, CareFusion, San Diego, California.
} 
1. Copnell B, Tingay DG, Kiraly NJ, Sourial M, Gordon MJ, Mills JF, et al. A comparison of the effectiveness of open and closed endotracheal suction. Intensive Care Med 2007;33(9):1655-1662.

2. Kiraly NJ, Tingay DG, Mills JF, Morley CJ, Dargaville PA, Copnell B. The effects of closed endotracheal suction on ventilation during conventional and highfrequency oscillatory ventilation. Pediatr Res 2009;66(4):400-404.

3. Tingay DG, Copnell B, Grant CA, Dargaville PA, Dunster KR, Schibler A. The effect of endotracheal suction on regional tidal ventilation and end-expiratory lung volume. Intensive Care Med 2010;36(5): 888-896.

Walsh: I don't necessarily disagree with that, but we tend to suction patients who are on HFOV less frequently, and maybe less appropriately, because we're so scared about lung volumes. Then we clog the ETT because we're so focused on FRC management, and we don't dare risk that, and yet they'll plug off the ETT in a heartbeat if you've gone a long time without suctioning. When I use an inline suction catheter, if I see oxygen saturation go up when I'm suctioning, I think that I over-distended them, and those secretions would probably come out better with a lower mean airway pressure, and maybe the best thing to do is take them off, lower their lung volume, and bag and suction them, then reestablish or reevaluate FRC again.

Branson: Having just written about this for another Journal Conference, ${ }^{1}$ I have a couple of comments. One is that I wouldn't call it CPT. What you're talking about is percussion and postural drainage, right? The problem with all these secretion-clearance studies is that they consider percussion and postural drainage the accepted standard when there's no evidence that percussion and postural drainage works at all. So other studies should compare nothing or adequate humidification, and suctioning to whatever the new technique is.
The second thing is about closed suctioning. The negative pressure from the suction catheter triggers the ventilator, and the incoming gas forces the secretions away from the suction catheter. Lasocki et al showed that that's what happens, ${ }^{2}$ and I think it explains why more secretions are removed with open-circuit suctioning. They corrected that by increasing the suctioning pressure to $-300 \mathrm{~mm} \mathrm{Hg}$ in adults. I look at what the therapists do every day, and it seems to me that if your technique doesn't allow the patient to get a big breath and then a forcible exhalation like a cough-if you can't stimulate a cough, then all these other high-frequency chest-wall compressions and whatever else don't do anything to assist with secretion removal in the ventilated patient.

1. Branson RD. Patient-ventilator interaction: the last 40 years. Respir Care 2011;56(1): 15-22; discussion 22-24.

2. Lasocki S, Lu Q, Sartorius A, Fouillat D, Remerand F, Rouby JJ. Open and closed endotracheal tube suctioning in acute lung injury: efficiency and effects on gas exchange. Anesthesiology 2006;104(1):39-47.

Walsh: I agree. You need the air behind the mucus to push it out to the main airway where you can suction it. Intrapulmonary percussive ventilation is intriguing; I think it does that by using fairly large volumes. That's why I'm not very supportive of the VDR [volumetric diffusive respiration] ventilation mode, because I' $m$ worried that it is delivering large tidal volumes chronically, but I am supportive of using it intermittently, say every 4 hours, with a ventilator to help remove secretions, because then it's just another airway-clearance device: not a ventilation mode.

Curley: I think it's important to recognize that we don't have a lot of good evidence on many elements of the suctioning guidelines. ${ }^{1}$ Can you comment on hyperventilation, hyperoxygenation, and the use of higher $\mathrm{V}_{\mathrm{T}}$ during suctioning?
1. AARC Clinical Practice Guidelines. Endotracheal suctioning of mechanically ventilated patients with artificial airways: 2010 . Respir Care 2010;55(6):758-764.

Walsh: I tried to cover a diverse patient population, but in neonates hyperoxygenation and hyperventilation is not safe and probably not in vogue. One of the things I think we've learned in suctioning neonates is how to manipulate the ventilator to re-recruit the lungs rather than allowing them to desaturate. We might turn up the PEEP and come back 15 minutes later and the lungs are re-recruited, but now the patient's oxygen saturation is dangerously high. If you spend more time at the bedside before and after suctioning, you could alleviate a lot of that and manipulate the ventilator to keep the $\mathrm{V}_{\mathrm{T}}$ consistent.

Outside of the neonatal ICU, with large- $\mathrm{V}_{\mathrm{T}}$ recruitment, it just depends on how much of an advocate you are and how much volutrauma it creates. Is it 5 breaths? Is it 10 breaths? I usually use $10 \mathrm{~mL} / \mathrm{kg}$ after suctioning to try to return the patient to baseline. Sometimes it takes 5-10 $\mathrm{cm} \mathrm{H}_{2} \mathrm{O}$ above on the ventilator to achieve that, but I try to stay below a peak pressure of $35 \mathrm{~cm} \mathrm{H}_{2} \mathrm{O}$ during re-recruitment maneuvers.

We have little evidence on recruitment maneuvers in children. In Boston we researched recruitment maneuvers, and I was impressed that sustained inflations tended not to work very well. A plateau pressure of $40 \mathrm{~cm} \mathrm{H}_{2} \mathrm{O}$ for 40 seconds is just not long enough to recruit the whole lung. It takes time, and you have to sit there. In pediatric patients outside of the cardiac ICU, I think it's fine to pre-oxygenate them.

I would like the therapist to focus more on the physiology of why you're having to use a higher $\mathrm{F}_{\mathrm{IO}_{2}}$ to get the $\mathrm{S}_{\mathrm{pO}_{2}}$ up, and to not to leave the bedside if the patient's not back down to their baseline $\mathrm{F}_{\mathrm{IO}_{2}}$. If they aren't, then we did something wrong and we need to either re-recruit the lungs 
or make other changes to the ventilator.

Brown: Thank you for including the study on suctioning and VAP prevention, ${ }^{1}$ which was interesting to me because I see the wholesale banning of suctioning in the neonatal ICU because of concern about VAP prevention. The theory is that biofilm forms in the ETT, and when we suction and lavage, we wash the biofilm down into the lungs. In that study, which was in adults, they theorized the opposite, that the lavage clears and prevents the biofilms. After being a therapist for many years and seeing how some practices we adopted ended up hurting our patients, I think it's interesting that the jury's still out. We don't really know if suctioning promotes or prevents VAP. I hate to see practice change before we know what we're doing or why.

1. Caruso P, Denari S, Ruiz SA, Demarzo SE, Deheinzelin D. Saline instillation before tracheal suctioning decreases the incidence of ventilator-associated pneumonia. Crit Care Med 2009;37(1):32-38

Myers: Regarding the financial aspect, remember that, regardless of the device or method, airway clearance is billed under one Current Procedural Terminology billing code number. We push an initiative to build an airwayclearance algorithm that starts with the cheapest airway-clearance technique and monitors the outcomes, and if it's not working, you step it up to the next category. There is no evidence supporting one device over the other, so it's a way to maximize that profit and time value of the resources and the devices.

Cheifetz: I completely agree. 